\title{
Review Article \\ Chronic Inflammation and Cytokines in the Tumor Microenvironment
}

\author{
Glauben Landskron, ${ }^{1}$ Marjorie De la Fuente, ${ }^{1}$ Peti Thuwajit, ${ }^{2}$ \\ Chanitra Thuwajit, ${ }^{2}$ and Marcela A. Hermoso ${ }^{1}$ \\ ${ }^{1}$ Disciplinary Program, Institute of Biomedical Sciences, School of Medicine, University of Chile, Independencia 1027, \\ 8380453 Santiago, Chile \\ ${ }^{2}$ Department of Immunology, School of Medicine, Siriraj Hospital, Mahidol University, 2 Prannok Road, Bangkok Noi, \\ Bangkok 10700, Thailand
}

Correspondence should be addressed to Marcela A. Hermoso; mhermoso@med.uchile.cl

Received 10 February 2014; Accepted 15 April 2014; Published 13 May 2014

Academic Editor: Evelin Grage-Griebenow

Copyright ( 2014 Glauben Landskron et al. This is an open access article distributed under the Creative Commons Attribution License, which permits unrestricted use, distribution, and reproduction in any medium, provided the original work is properly cited.

Acute inflammation is a response to an alteration induced by a pathogen or a physical or chemical insult, which functions to eliminate the source of the damage and restore homeostasis to the affected tissue. However, chronic inflammation triggers cellular events that can promote malignant transformation of cells and carcinogenesis. Several inflammatory mediators, such as TNF- $\alpha$, IL-6, TGF- $\beta$, and IL-10, have been shown to participate in both the initiation and progression of cancer. In this review, we explore the role of these cytokines in important events of carcinogenesis, such as their capacity to generate reactive oxygen and nitrogen species, their potential mutagenic effect, and their involvement in mechanisms for epithelial mesenchymal transition, angiogenesis, and metastasis. Finally, we will provide an in-depth analysis of the participation of these cytokines in two types of cancer attributable to chronic inflammatory disease: colitis-associated colorectal cancer and cholangiocarcinoma.

\section{Introduction}

The role of inflammation in the development of cancer was described as early as 1863 , by Rudolf Virchow. His observations that inflammatory cells infiltrate tumors led him to hypothesize that cancer arises from inflammatory sites ("lymphoreticular infiltration") [1,2]. In the last decades, Virchow's postulation has been supported by abundant evidence that various cancers are triggered by infection and chronic inflammatory disease [3].

Inflammation is a beneficial response activated to restore tissue injury and pathogenic agents. However, if inflammation is unregulated, it can become chronic, inducing malignant cell transformation in the surrounding tissue. The inflammatory response shares various molecular targets and signaling pathways with the carcinogenic process, such as apoptosis, increased proliferation rate, and angiogenesis. Furthermore, the use of nonsteroidal anti-inflammatory drugs (NSAIDs) has been shown to decrease incidence and mortality of several cancers [4].

In relation to chronic inflammatory-associated neoplasias, this review article explores the involvement of cytokines in chronic inflammation and carcinogenesis, focusing on inflammatory bowel disease-associated cancer and cholangiocarcinoma (CCA) induced by chronic inflammation of biliary ducts, that is, primary sclerosing cholangitis (PSC) and liver fluke associated-CCA. Both cancers are examples of a localized, long-term inflammatory process increasing the risk of cancer.

\section{Chronic Inflammation as an Inducer of Tumors}

The immune response comprises a series of events triggered in response to recognition of pathogens or tissue damage, involving cells and soluble mediators, such as cytokines of 
the innate and adaptive immune system. The main purpose of this inflammatory response is to remove the foreign agent disturbing tissue homeostasis [5]. In the normal physiological context, after tissue repair or pathogen elimination, the inflammation is resolved and the homeostatic state recovered [6].

It is now widely accepted that inadequately resolved chronic inflammation may increase the risk of cancer. Several pathologies illustrate this link, such as endometriosis, chronic prostatitis, and chronic gastritis due to Helicobacter pylori (H. pylori), inflammatory bowel diseases (IBD), and primary sclerosing cholangitis (PSC) (Table 1). Inflammation can increase the risk of cancer by providing bioactive molecules from cells infiltrating the tumor microenvironment, including cytokines; growth factors; chemokines that maintain a sustained proliferative rate; cell survival signals to avoid apoptosis; proangiogenic factors; and extracellular matrixmodifying enzymes such as metalloproteinases that promote epithelial-mesenchymal transition (EMT) and facilitate other carcinogenesis programs, such as genome instability, reprogramming of energy metabolism, and immune evasion [7]. Here, we focus on key cytokines involved in tumor induction and their role in EMT, angiogenesis, invasion, and metastasis.

\section{Cytokines Involved in Tumor Development}

Cytokines are low-molecular-weight proteins that mediate cell-to-cell communication. Immune and stromal cells, such as fibroblasts and endothelial cells, synthesize them and they regulate proliferation, cell survival, differentiation, immune cell activation, cell migration, and death. Depending on the tumor microenvironment, cytokines can modulate an antitumoral response, but during chronic inflammation, they can also induce cell transformation and malignancy, conditional on the balance of pro- and anti-inflammatory cytokines, their relative concentrations, cytokine receptor expression content, and the activation state of surrounding cells [50].

3.1. Tumor Necrosis Factor (TNF- $\alpha$ ). As noted, unresolved inflammation can lead to malignancy. Tumor necrosis factor (TNF- $\alpha)$ is one inflammatory mediator that has been implicated in carcinogenesis, due to its participation in chronic inflammatory diseases [51]. Moore et al. provided evidence that TNF- $\alpha$-deficient mice are resistant to tetradecanoylphorbol-13-acetate- (TPA-) induced skin carcinogenesis. TNF- $\alpha$ effect seems to be more significant in the early stages of carcinogenesis, including angiogenesis and invasion, versus progression of carcinogenesis $[52,53]$. While TNF- $\alpha$ is a prototypical proinflammatory cytokine, evidence suggests a double-edged role in carcinogenesis. This cytokine is recognized by two receptors: TNF- $\alpha$ receptor- 1 (TNF- $\alpha$ R1 ), ubiquitously expressed, and TNF- $\alpha \mathrm{R}-2$, expressed mainly in immune cells [54]. Trimerization occurs upon TNF- $\alpha$ binding to TNF- $\alpha$-Rs, leading to activation of at least four signaling pathways: a proapoptotic pathway induced by caspase8 interaction with Fas-associated death domain (FADD); an antiapoptotic platform activated by cellular inhibitor of apoptosis protein-1 (cIAP-1) and interacting with TNF- $\alpha$ Rassociated factor 2 (TRAF2); a TRAF2- and JNK-mediated
AP-1 signaling pathway; and a receptor interacting protein(RIP-) induced NF- $\kappa \mathrm{B}[54]$.

There is controversy, however, regarding the role of TNF$\alpha$ in cancer; high concentrations of this cytokine can induce an antitumoral response in a murine model of sarcoma [55]. Furthermore, William B. Coley, a pioneer surgeon in the field, discovered that there was a reliable treatment response for systemic bacterial filtrate injection in sarcoma patients [55, 56]. However, severe toxic side effects have been associated with systemically administered TNF- $\alpha$, such as hypotension and organ failure [57]. Local administration has been shown to be safer and effective, as demonstrated by clinical trials evaluating a TNF- $\alpha$-expressing adenovirus (TNFerade) gene therapy combined with chemotherapy $[58,59]$. Moreover, TNF- $\alpha$-conjugate targeting peptides or single-chain antibody fragments have also shown variable effects, depending on the patient [60].

In contrast, low, sustained TNF- $\alpha$ production levels can induce a tumor phenotype [61]. A TNF- $\alpha$ tumor promotion mechanism is based on reactive oxygen species (ROS) and reactive nitrogen species (RNS) generation, which can induce DNA damage, hence facilitating tumorigenesis [62, 63]. TNF$\alpha$-mediated inflammation has been linked to cancer; for instance, increased TNF- $\alpha$ levels in preneoplastic lesions have been detected in $H$. pylori-positive gastric lesions, through $H$. pylori-secreted TNF- $\alpha$-inducing protein (Tip $\alpha)[64,65]$.

A study by Kwong et al. explored TNF- $\alpha$-associated tumorigenesis using an organoid of normal human ovarian epithelial cells exposed to a prolonged TNF- $\alpha$ dose. The model demonstrated generation of a precancerous-like phenotype with structural and functional changes, such as tissue disorganization, epithelial polarity loss, cell invasion, and overexpression of cancer markers [66].

According to these findings, the pro- or antitumoral TNF$\alpha$ response within the tumor microenvironment depends not only on local concentration but also on its expression site in the tumor. Patients with elevated levels of TNF- $\alpha$ in tumor islets from non-small cell lung cancer, mainly restricted to macrophages and mast cells, showed the highest survival rates, while patients with increased stromal TNF- $\alpha$ content showed lower survival rates [67].

There is also evidence that prolonged TNF- $\alpha$ exposure can enhance the proportion of cancer stem cell phenotypes in oral squamous cell carcinoma, increasing their tumorforming sphere ability, stem cell-transcription factor expression, and tumorigenicity [68].

3.2. Interleukin 6 (IL-6). Another proinflammatory cytokine with a typical protumorigenic effect is IL-6. Elevated serum IL-6 levels have been detected in patients with systemic cancers as compared to healthy controls or patients with benign diseases. IL- 6 has been proposed as a malignancy predictor, with sensitivity and specificity of about $60-70 \%$ and 58-90\%, respectively [69]. However, there are limited studies available that might be used to define cut-off values for IL-6 as a diagnostic tool.

IL-6 plays a key role in promoting proliferation and inhibition of apoptosis, by binding to its receptor (IL-6R $\alpha$ ) 
TABLE 1: Cancer associated with chronic inflammatory disorders.

\begin{tabular}{|c|c|c|}
\hline Cancer & Associated inflammatory stimuli & Reference \\
\hline Colorectal cancer/colitis-associated cancer & Inflammatory bowel diseases (ulcerative colitis and Crohn's diseases) & {$[8]$} \\
\hline Cholangiocarcinoma & Liver fluke and primary sclerosing cholangitis & [9] \\
\hline Gastric cancer & Chronic gastritis (H. Pylori) & [10] \\
\hline Lung cancer & Inflammation caused by asbestos, infections, smoking, and silica & [11] \\
\hline Prostate cancer & E. coli infection of prostate & {$[12]$} \\
\hline Hepatocellular carcinoma & Infection with hepatitis virus $B$ and hepatitis virus $C$ & [13] \\
\hline Melanoma & UV irradiation-associated skin inflammation & [14] \\
\hline Endometrial carcinoma & Endometriosis & {$[15]$} \\
\hline Gall bladder carcinoma & Gall bladder stone-associated chronic cholecystitis & {$[16,17]$} \\
\hline Esophageal cancer & Barrett's esophagitis & [18] \\
\hline
\end{tabular}

and coreceptor gp130 (glycoprotein 130), thus activating the JAK/STAT signaling pathway of the Janus kinases (JAK) and signal transducers and activators of transcription (STATs) STAT1 and STAT3 [70]. STATs belong to a family of transcription factors closely associated with the tumorigenic processes. Several studies have highlighted the effect of the IL6/JAK/STAT signaling pathway on cancer initiation and progression. IL-6 can induce tumorigenesis by hypermethylation of tumor suppressor genes as well as by hypomethylation of retrotransposon long interspersed nuclear element-1 (LINE1) in oral squamous cell cancer lines in vitro [71], a frequent event in various human cancers. Furthermore, IL-6 has been shown to be produced primarily by stromal fibroblasts in a gastric cancer mouse model; however, the deficient mouse model exhibits reduced tumorigenesis when exposed to the carcinogen $\mathrm{N}$-methyl-N-nitrosourea [72].

IL-6 has a role in multiple myeloma development, as demonstrated by its ability to induce apoptosis by blocking the IL-6R/STAT3 pathway in vitro [73] and the resistance of IL- $6^{-/-}$mice to plasmacytoma induction [74].

Like TNF- $\alpha$, IL- 6 facilitates tumor development by promoting conversion of noncancer cells into tumor stem cells. In particular, IL- 6 secretion by noncancer stem cells in lowattachment culture conditions upregulates Oct4 gene expression by activating the IL-6R/JAK/STAT3 signaling pathway [75].

These findings have led researchers to propose IL-6 as a therapeutic target in cancer. Several phase I/II clinical trials are currently evaluating antibodies against IL-6 or IL$6 \mathrm{R}$ as therapeutic alternatives. Siltuximab (CNTO 328), a monoclonal antibody against IL-6, has shown promising results for non-small cell lung cancer, ovarian cancer, prostate cancer, and multiple myeloma, among others [76-80].

In this context, as inflammatory cytokines are partially responsible for tumor induction, an increase in antiinflammatory cytokines should limit the risk of cancer and reduce activation of signaling pathways. Nonetheless, evidence suggests that anti-inflammatory cytokines, such as TGF- $\beta$ and IL-10, show more complex effects on tumor development.

3.3. Transforming Growth Factor $\beta$ (TGF- $\beta$ ). TGF- $\beta$ is a powerful pleiotropic cytokine, with immune-suppressing and anti-inflammatory properties. Under physiological conditions, TGF- $\beta$ has a well-documented role in embryogenesis, cell proliferation, differentiation, apoptosis, adhesion, and invasion [81]. Three isoforms have been identified: TGF- $\beta 1$, TGF- $\beta 2$, and TGF- $\beta 3$. TGF- $\beta$ s binds to the cognate type II receptor (TGF- $\beta$ RII), inducing type I TGF- $\beta$ receptor (TGF$\beta \mathrm{RI}$ ) phosphorylation and leading to the formation of a heterotetrameric complex that activates SMAD-dependent transcription [82]. SMAD transcription factors are structurally formed by a serine and threonine-rich linker region that connects two MAD (mothers against dpp) homology regions. Differential phosphorylation of these amino acid residues contributes to various cellular functions, including cytostatic effects, cell growth, invasion, extracellular matrix synthesis, cell cycle arrest, and migration [83]. Therefore, differential phosphorylation of SMAD2 and SMAD3 by TGF$\beta$ receptor activation promotes their translocation into the nucleus, where they form a complex with SMAD4, further bind to DNA, associate with other transcription factors, and induce gene expression [82].

The role of TGF- $\beta$ in cancer is complex and paradoxical, varying by cell type and stage of tumorigenesis. In early stages, TGF- $\beta$ acts as a tumor suppressor, inhibiting cell cycle progression and promoting apoptosis. Later, TGF- $\beta$ enhances invasion and metastasis by inducing epithelial-mesenchymal transition (EMT) [84]. In cancer induction, TGF- $\beta$ exerts a tumor suppressor effect through cyclin-dependent kinase inhibitor (CKI) p21 upregulation and c-Myc downregulation [85]. Using a conditional TGF- $\beta$ RII knock-out mice model, Guasch et al. found that highly proliferative epithelia (such as rectal and genital) developed spontaneous squamous cell carcinomas and furthermore showed accelerated carcinoma progression, Ras mutations, and apoptosis reduction [86], suggesting that a deficient TGF- $\beta$ pathway contributes to tumorigenesis.

There is consistent evidence demonstrating that TGF- $\beta$ signaling changes are involved in human cancer. Increased TGF- $\beta 1 \mathrm{mRNA}$ and protein have been observed in gastric carcinoma, non-small cell lung cancer, and colorectal and prostate cancer [87], and TGF- $\beta$ receptor deletion or mutations have been associated with colorectal, prostate, breast, and bladder cancer, correlating with a more invasive and advanced carcinoma, higher degree of invasion, and worse prognosis [88]. 
In the tumor microenvironment, common sources of TGF- $\beta$ are cancer and stromal cells, including immune cells and fibroblasts [82]. Bone matrix is also an abundant source of TGF- $\beta$ and a common site for metastasis in many cancers, correlating with the tumor-promoting and invasive effects of this cytokine [89].

Specific therapy targeting this cytokine in advanced cancer patients has shown promising results in preclinical and clinical studies, using TGF- $\beta$ inhibitors, specifically ligand traps, antisense oligonucleotides, receptor kinase inhibitors, and peptide aptamers. Nevertheless, serious side effects of systemic TGF- $\beta$ inhibitors administration have been reported, indicating that further clinical trials are required to evaluate localized, safe, dose-effective therapies [89].

3.4. Interleukin 10 (IL-10). Interleukin 10 (IL-10) is known to be a potent anti-inflammatory cytokine. Almost all immune cells, including $\mathrm{T}$ cells, B cells, monocytes, macrophages, mast cells, granulocytes, dendritic cells, and keratinocytes, produce IL-10 [90]. Tumor cells can also secrete IL-10, as can tumor-infiltrating macrophages [91, 92].

When IL-10 binds to its receptor, Jak1 and Tyk2 tyrosine kinases phosphorylate an IL-10R intracellular domain, allowing it to interact with STAT1, STAT3, and STAT5, favoring STAT translocation into the nucleus and induction of target gene expression [93].

Several studies have indicated that IL-10 has both pro- and antitumoral effects. IL-10 inhibits NF- $\kappa \mathrm{B}$ signaling; therefore, it can downregulate proinflammatory cytokine expression [94] and act as an antitumoral cytokine. Consistent with this finding, Berg et al. demonstrated that IL-10-deficient murine models are prone to bacteria-induced carcinogenesis [95], whereas the adoptive transfer of IL-10-expressing $\mathrm{CD}^{+} \mathrm{CD}^{2} 5^{+} \mathrm{T}$ cells into Rag2 ${ }^{-/-}$(lymphocyte-deficient) mice inhibits colorectal inflammation and carcinomas [96, 97]. Moreover, IL-10 can exert antitumoral activity in gliomas, melanomas, and breast and ovarian carcinomas [98], through a mechanism involving MHC-I downregulation, thus inducing NK-mediated tumor cell lysis [99].

Due to its immunosuppressive effect on dendritic cells and macrophages, IL-10 can dampen antigen presentation, cell maturation, and differentiation, allowing tumor cells to evade immune surveillance mechanisms [100].

In addition and as previously described for IL-6, STAT3 can also be activated by IL-10, although the cytokines' contradictory responses are determined by receptor and time frame of STAT activation. In particular, IL-6 leads to a transient, rapidly declining STAT3 phosphorylation and nuclear localization, whereas IL-10 induces a sustained STAT3 phosphorylation [101]. Through STAT3 activation, IL10 can also have a protumorigenic effect, mediated by an autocrine-paracrine loop [102] involving Bcl-2 upregulation and apoptosis resistance activation [103, 104]. Likewise, elevated IL-10 levels are associated with poor prognosis in diffuse B cell lymphoma [105] and expression by tumor cells, and tumor-associated macrophages promote Burkitt's lymphoma through the increased production of a TNF- $\alpha$ family member, BAFF, a tumor growth/survival molecule [106].

\section{Inflammatory Response and Malignancy}

4.1. Inflammation-Induced Reactive Oxygen Species (ROS) and Reactive Nitrogen Species (RNS) in the Carcinogenic Process. In an inflammatory response, epithelial and immune cell activation trigger ROS and RNS generation through induction of NADPH oxidase and nitric oxide synthase (NOS), respectively. NADPH oxidase is a protein complex composed of several membrane-associated subunits that catalyze the superoxide anion $\left(\mathrm{O}_{2}^{-\bullet}\right)$, leading to superoxide dismutase(SOD-) mediated hydrogen peroxide $\left(\mathrm{H}_{2} \mathrm{O}_{2}\right)$ production. NADPH oxidase is expressed in phagocytic and nonphagocytic cells, and cytochrome subunit isoforms are present in different cell types (NOX2 in phagocytic cells, such as macrophages and neutrophils) (NOX1, 3-5, and DUOX1, 2 in nonphagocytic cells) [107]. On the other hand, NOS generates nitric oxide (NO) from L-arginine, which can be converted into RNS such as nitrogen dioxide $\left(\mathrm{NO}_{2}^{*}\right)$, peroxynitrite $\left(\mathrm{ONOO}^{-}\right)$, and dinitrogen trioxide $\left(\mathrm{N}_{2} \mathrm{O}_{3}\right)$. Different NOS isoforms are produced depending on cell type: inducible NOS (iNOS) in phagocytic cells and constitutive in endothelial and neuronal (eNOS and nNOS) cells [108]. ROS and RNS have a potent antimicrobial role in phagocytic cells and also act as a second messenger in signaling transduction $[109,110]$.

Phagocytic cell activation can directly induce reactive oxygen and nitrogen species (collectively called RONS), activating NOX2, NADPH oxidase, and iNOS [109]. Furthermore, TNF- $\alpha$, IL- 6 , and TGF- $\beta$ trigger RONS generation in nonphagocytic cells [111-113].

Increased expression of NADPH oxidase and NOS and their products RONS has been identified in various cancers, suggesting that free radicals have a role in genesis and malignant progression [63]. In various chronic inflammatory diseases, such as $H$. pylori-associated gastritis and inflammatory bowel diseases (IBD), high RONS levels have been observed, suggesting a role in cancer risk [114-116].

Different mechanisms have been proposed to clarify RONS participation in cancer development. RONS induce cell oxidative stress and damage of lipids, proteins, and DNA, as well as production of 8-oxo-7, 8-dihydro- $2^{\prime}$ deoxyguanosine (8-oxodG), which is actually used as a DNA damage marker. Furthermore, 8-oxodG can pair with adenine, leading to transversion of $\mathrm{G}: \mathrm{C}$ to $\mathrm{T}: \mathrm{A}(\mathrm{G} \rightarrow \mathrm{T}$ transversion). Similarly, $\mathrm{ONOO}^{-}$can modify deoxyguanosine to 8-nitrodeoxyguanosine, which can spontaneously generate an apurinic site, favoring $\mathrm{G} \rightarrow \mathrm{T}$ transversion [19]. Identification of these DNA damage markers in chronic inflammatory processes, such as $H$. pylori-associated gastritis, hepatitis, and ulcerative colitis, emphasizes the relevance of RONS in pathologies with an increased risk of cancer (Figures 1(a) and 1(b)) [19, 117, 118]. Moreover, 8-oxodG and 8 -nitrodeoxyguanine immune-reactivity is increased in the liver of hepatitis $\mathrm{C}$ virus-derived chronic hepatitis patients [118].

Jaiswal et al. found increased iNOS, 3-nitrotyrosine, and 8-oxodG in the livers of primary sclerosis cholangitis (PSC) patients [119]. Furthermore, RNS interfere with DNA repair, as shown in cells overexpressing iNOS that are unable to repair modified 8-oxodG [119]. Deficient DNA-repair 


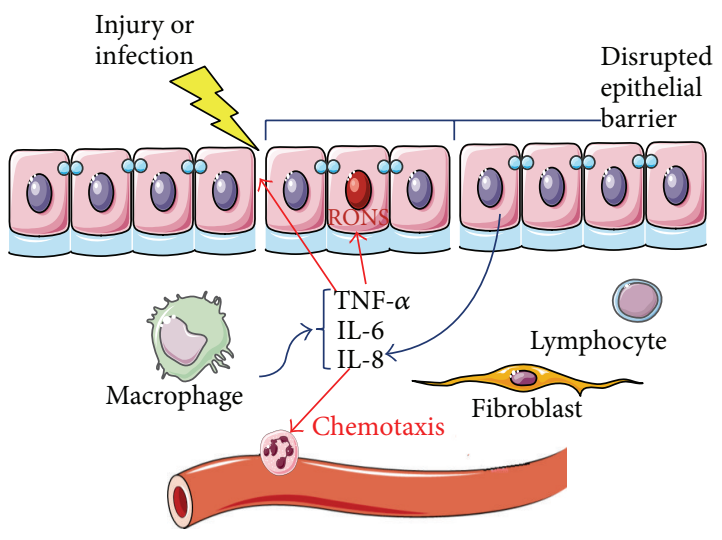

(a)

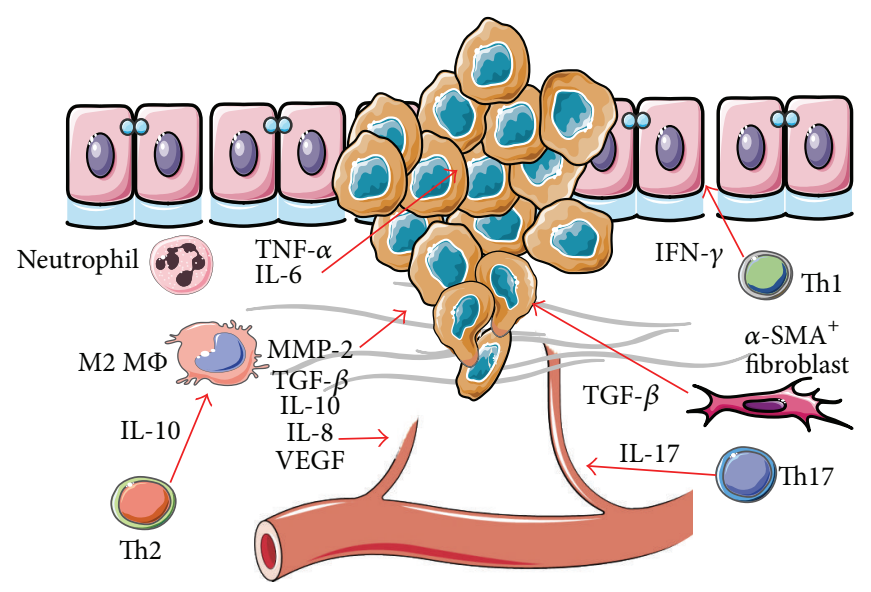

(c)

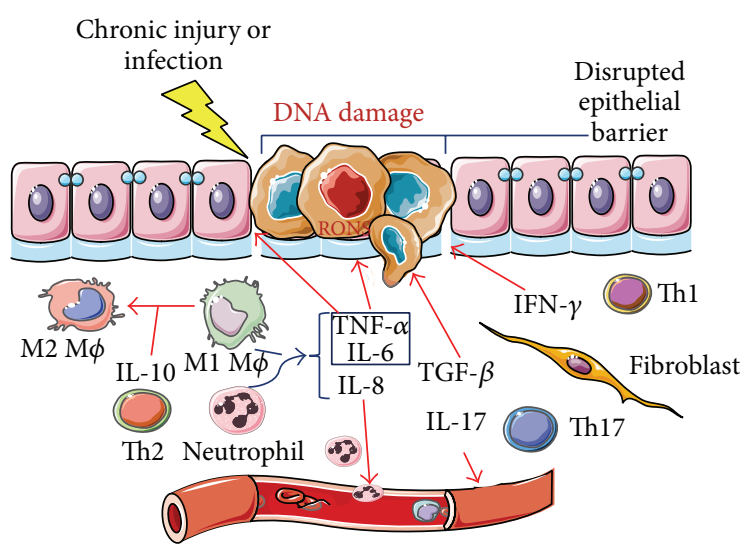

(b)

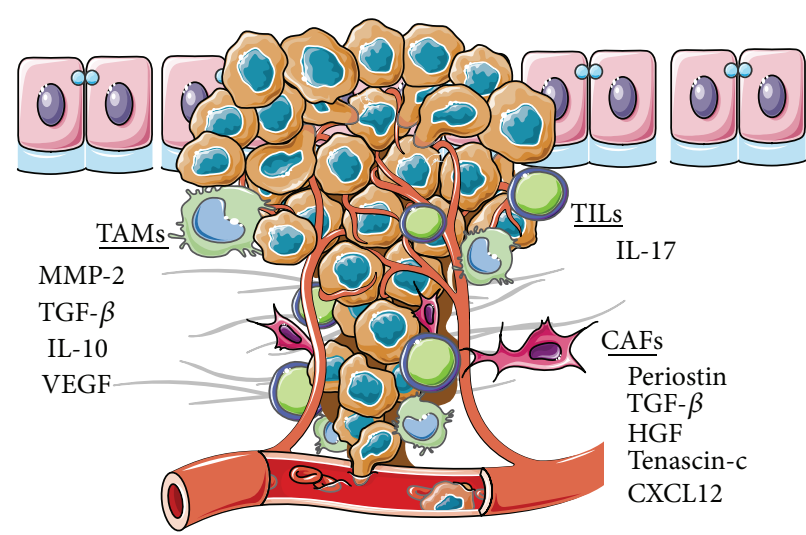

(d)

FIGURE 1: Schematic illustration of the role of cytokines in carcinogenesis. (a) During tissue injury or infection, an immune response activates the expression of proinflammatory mediators, such as TNF- $\alpha$, IL-6, and IL- 8 from macrophages and neutrophils. These cytokines can disrupt the epithelial barrier, induce RONS, and promote the infiltration of other inflammatory cells. (b) In chronic inflammation, proinflammatory cytokines such as TNF- $\alpha$ can induce DNA damage through RONS, which leads to tumor initiation. TGF- $\beta$ can promote malignant transformation through EMT activation. Cytokines derived from CD4 ${ }^{+}$lymphocytes, such as IFN- $\gamma$, IL-10, and IL-17, can participate in epithelial barrier disruption, M2 phenotypic transitions of macrophages, and angiogenesis, respectively. (c) Tumor growth and invasion are also favored by proinflammatory cytokines that stimulate cell proliferation, reduce apoptosis, and enhance EMT and angiogenesis; the latter is facilitated by VEGF and IL-8. Anti-inflammatory cytokines, such as IL-10 and TGF- $\beta$, contribute to tumor immune evasion. (d) Tumorassociated macrophages (TAM), tumor-infiltrating lymphocytes (TIL), and cancer-associated fibroblasts (CAF) secrete several factors that contribute to tumor growth and metastasis, while maintaining the immunosuppressive milieu.

protein activity has been linked to enzyme S-nitrosylation, attributable to increased RNS [120].

RONS are generated by cellular stress and macromolecule modification, although they are also involved in the regulation of signaling pathways, such as survival and cell proliferation through Akt, Erk1/2, and hypoxia-inducible factor-1 (HIF-1) activation [121, 122].

There is strong evidence linking carcinogenesis to inflammatory response and RONS, and therapeutic strategies for cancer prevention using free radicals and proinflammatory signaling inhibitors have been evaluated in animal models [123-125].

4.2. Inflammation-Associated Tumor Growth. Nowadays, it is accepted that chronic inflammation is important in generating malignancy through the exposure of proinflammatory cytokines and sustained activation of signaling pathways such as NF- $\kappa \mathrm{B}$ and STAT3. Following cell transformation to a malignant state, these cytokines are also involved in tumor growth, by stimulating the proliferation of tumor cells and by evading immunosurveillance (Figures 1(b) and 1(c)).

Several cytokines have growth factor activity; a relevant cytokine is TNF- $\alpha$. In a study by Zhu et al., they showed that the silencing of TNF- $\alpha$ in a gallbladder cell line decreases cell proliferation and invasion by an autocrine effect, affecting the activation of TNF- $\alpha / \mathrm{NF}-\kappa \mathrm{B} / \mathrm{AKT} / \mathrm{Bcl}-2$ pathway in these cells [126]. This is consistent with data previously observed by Luo et al. who revealed that NF- $\kappa \mathrm{B}$ signaling is required to promote tumor cell proliferation in response to an inflammatory stimulus, and by inhibiting this transcription factor, an antitumor signal led by TNF- $\alpha /$ TRAIL is triggered [20]. However, in a mouse model of ovarian cancer, TNF- $\alpha$ can 
also stimulate the secretion of other cytokines like IL-17 by $\mathrm{CD}^{+} \mathrm{T}$ cells and promote tumor growth indirectly [127].

The protumorigenic role of IL-17 has also been implicated in other types of cancer. In mice with carcinogen-induced skin tumors, those deficient in IL-17 receptor showed a lower tumor incidence and a diminished tumor size [128].

IL-6 is another typical proinflammatory cytokine with tumor growth effect, mainly by activating JAK tyrosine kinases and the transcription factor STAT3, as seen in lung, kidney, and breast cancer in which a high expression of STAT3 has been identified [70]. Also, in cell lines of malignant fibrous histiocytoma, a high secretion of IL- 6 and constitutive activation of STAT3 were reported, reflecting an increase of tumor cell proliferation [129].

In cancer, other molecules that may influence tumor growth by regulating the IL-6/STAT3 signaling pathway have been reported. Inflammatory mediators like Hmgbl, IL-23, and IL17 can promote tumor growth by activating IL-6/STAT3 pathway in a mouse model of melanoma [130]. In cholangiocarcinoma, a high expression of the tumor suppressor gene regulator, gankyrin, favors tumor proliferation, invasion, and metastasis through activation of IL-6/STAT3 signaling pathway [131]. Furthermore, embelin, a derivative from Embelia ribes, is known to inhibit XIAP (X-linked inhibitor of apoptosis protein) and is able to impair tumor proliferation by interfering in IL-6/STAT3 signaling [132].

Finally, the anti-inflammatory cytokine IL-10 may also contribute to tumor growth. In a mouse model of melanoma, tumors overexpressing IL-10 present a higher tumor growth mediated by an increase in tumor cell proliferation, angiogenesis, and immune evasion [133].

\subsection{Inflammation-Associated Epithelial Mesenchymal Tran-} sition. The epithelial mesenchymal transition (EMT) is an important process of cellular reprogramming during embryogenesis and pathological events such as inflammation, wound healing, and cancer [134, 135]. During EMT, epithelial cells exhibit morphological changes, acquiring fibroblast characteristics. In this process, structures involved in epithelial cell-cell interaction, such as tight junctions, adherens junctions, desmosomes, and gap junctions, are lost, and the cells undergo actin cytoskeleton reorganization and changes in the expression profile of proteins allowing for cellcell contact, such as E-cadherin. Furthermore, expression of fibroblast markers, including fibronectin, $\alpha$-smooth muscle actin ( $\alpha$-SMA), and matrix metalloproteinases, is favored during EMT. Cellular reprogramming is orchestrated by a variety of transcription factors, such as Snail, ZEB, and the helix-loop-helix (HLH) family [136, 137]. The mesenchymal phenotype provides increased motility that is associated with invasiveness and metastasis of tumor cells $[138,139]$.

One inflammatory mediator relevant in EMT is TGF- $\beta$, as demonstrated by its role in embryogenesis, fibrosis, and tumor development in various EMT models [137, 140-142]. SMAD2, SMAD3, and SMAD4 mediate EMT modulation via TGF- $\beta$ signaling [137], as shown by EMT inhibition in SMAD3-deficient mice and by SMAD2-, SMAD3-, or SMAD4-dominant negative constructs in vitro $[143,144]$. Extensive evidence supports the notion that EMT can be induced by proinflammatory cytokines. TNF- $\alpha$ and IL- 6 may synergistically nudge the TGF- $\beta$ signaling pathway towards EMT progression (Figures 1(b) and 1(c)) [21, 145]. Both cytokines promote NF- $\kappa \mathrm{B}$ activation, which regulates the expression of transcription factors involved in EMT, orchestrating the effects of Snaill, Snail2, Twist, ZEB1, and ZEB2 [146, 147]. Moreover, IL-6 induces cell invasiveness in EMT, through increased vimentin and downregulated Ecadherin expression, both mediated by the JAK/STAT3/Snail signaling pathway, as shown in head and neck cancer [148].

Finally, ROS production can promote EMT [149]; therefore, exposing kidney epithelial cells to ROS induces TGF- $\beta$ expression, the SMAD signaling pathway, and EMT, whereas antioxidants inhibit these processes [150].

4.4. Inflammation-Associated Angiogenesis. Angiogenesis comprises the processes leading to the generation of new blood vessels from an existing vascular network. Angiogenesis in cancer development is important because the new blood vessel network penetrates and supplies nutrients and oxygen to tumor cells. Several angiogenic factors secreted by tumor cells have been identified, in particular vascular endothelial growth factor (VEGF) that is expressed in response to cytokines and growth factors, as shown in Figures $1(\mathrm{c})$ and 1(d) [151]. Moreover, characterization of tumorassociated macrophages (TAM) obtained from metastatic lymph nodes (MLN) in an animal model of melanoma has shown that MLN are constituted predominantly by $\mathrm{TIE}^{+} / \mathrm{CD} 31^{+}$infiltrating macrophages. This subpopulation significantly overexpresses VEGF and is directly related to angiogenesis [152].

Fajardo et al. showed that TNF- $\alpha$ might have a doubleedged role in angiogenesis, depending on the dose used. High TNF- $\alpha$ doses inhibited angiogenesis in mice subcutaneously implanted with an angiogenesis disc-system, an experimental strategy used to induce new blood vessels, while low doses promoted vascularization of the area [153]. The antiangiogenic effect of TNF- $\alpha$ is related to downregulation of $\alpha \nu \beta 3$ and the angiotensin signaling pathway [154], while proangiogenic responses have been associated with increased VEGF, VEGFR, IL-8, and FGF expression [155].

On the other hand, low TNF- $\alpha$ levels increase tumor growth, induce angiogenesis of diverse tumors in mice, and induce a subpopulation of tumor-associated myeloid cells coexpressing endothelial and myeloid markers with proangiogenic/provasculogenic properties [156].

The tumor source of TNF- $\alpha$ can be derived from myeloid or tumor cells and through an autocrine activation can stimulate tumor growth and angiogenesis [157]. Likewise, tumors derived from TNF- $\alpha$ knockdown cells have a wellcircumscribed phenotype, with low vascularization and less invasiveness [157].

Another relevant angiogenic factor is IL-6; high levels correlate with VEGF content in colorectal and gastric cancer $[158,159]$. Moreover, IL-6 induces VEGF expression in a dose-dependent manner in gastric cancer cell lines [160]. Similarly, IL-6 promotes angiogenesis by activating 
the STAT3 pathway in cervical cancer [161]. Together, IL6 secretion and the subsequent STAT3 phosphorylation are involved in the upregulation of angiogenic mediators, such as VEGF, HIF1 $\alpha$, the VEGFR2 coreceptor, and neuropilin 2 (NRP2) $[162,163]$. In xenograft models of ovarian cancer, reduced tumor neovascularization, TAM infiltration, and chemokine production were demonstrated after a challenge with siltuximab, a high-affinity anti-IL-6 antibody [77].

A proangiogenic effect has also been attributed to TGF- $\beta$ [88]. High TGF- $\beta$ levels in tumors correlate with angiogenesis in prostate cancer [164]. In addition, TGF- $\beta$ levels correlate with VEGF expression in gastric carcinoma [165]. These data are consistent with the defective vasculogenesis shown in TGF- $\beta 1$ knockdown mice [166].

On the other hand, anti-inflammatory IL-10 has been suggested to have an antiangiogenic role in several cancer models $[167,168]$. Overexpression of mIL-10 in the KOC-2S tumor cell line had little effect on the VEGF-hyposecretory phenotype, suggesting that mIL-10-mediated inhibition of angiogenesis is mediated by VEGF [169].

4.5. Inflammation-Associated Metastasis. Metastasis is a process characterized by neoplastic cell spread to another organ of different origin. During metastasis, the cells invade blood and lymphatic vessels and circulate through the bloodstream, with subsequent retention in another organ, generating a new tumor focus.

The metastatic cascade is modulated by the action of several cytokines released by surrounding cells such as tumor associated macrophages, infiltrating lymphocytes, and cancer associated fibroblasts, promoting tumor cell evasion and dissemination; this process is depicted in Figure 1(d). The influence of TNF- $\alpha$ has been investigated in various experimental animal models. Administration of this cytokine leads to a significant increase of the number of lung metastases $[170,171]$. Kim et al. proposed that tumor cells activate myeloid cells to generate a microenvironment favorable for metastasis. In Lewis lung carcinoma (LLC) cell conditionedmedium, high levels of IL- 6 and TNF- $\alpha$ were induced in bone marrow-derived macrophages [172]. TNF- $\alpha^{-/-}$but not IL$6^{-/-}$mice injected with LLC cells showed improved survival and reduced lung tumor multiplicity, suggesting a critical role of TNF- $\alpha$ in LLC metastasis [172]. In accordance with these data, studies show that the use of anti-TNF- $\alpha$ antibodies aids in decreasing metastasis $[4,173]$. IL-6, in turn, is upregulated in various tumors and has been implicated in the capacity of cancer cells to metastasize to bone $[148,174,175]$.

In contrast, IL-10 displays an antitumoral function. Restitution of IL-10 in the A375P human melanoma cell line, which does not produce endogenous IL-10, using a vector containing murine IL-10 cDNA, reverted tumor growth and lung metastases. This evidence suggests that IL-10 production by tumor cells inhibits metastasis [167].

There is a strong relationship between EMT and metastasis, suggesting that, in the early stages of the metastatic cascade, EMT enables migration and intravasation of tumor cells [176]. For this reason, inflammatory mediators involved in EMT, in particular TGF- $\beta$, might play an important role in promoting metastasis [138].

\section{Colorectal Cancer and Inflammatory Bowel Disease}

Colorectal cancer is the third-most frequent cancer worldwide, with a higher incidence in developed countries [177]. A mortality rate of about $9 \%$ has been reported for both men and women, with 5 -year survival between $74 \%$ and $59 \%$ for early stages (stages I to IIC) and 6\% for stage IV [178].

Today it is widely accepted that IBD patients have a higher risk of CRC especially ulcerative colitis (UC) and to a much lesser extent Crohn's disease (CD). In a population-based study in the United States, standardized incidence ratios (SIR) of 2.4 (95\% IC 0.6-6.0) in extensive UC or pancolitis and 1.9 in CD (95\% IC 0.7-4.1) were reported [8]. The prevalence of CRC in UC patients in the Asia-Pacific region ranges from 0.3 to $1.8 \%$ [179]. In a Japanese study, poorer survival was observed in patients with ulcerative colitis-associated colorectal cancer as compared to sporadic colorectal cancer patients in advanced stages [180].

Risk factors involved in this process include a greater extent of compromised tissue and sustained disease duration with an onset of more than 7 years, with risk increasing $0.5-1.0 \%$ per year [181]. Another risk factor is concomitant primary sclerosing cholangitis (PSC) and UC, with an OR 4.79: $95 \%$ CI $(3.58,6.41)[182]$.

As noted previously, several types of cancer are associated with chronic infections (Table 1). The IBD are multifactorial pathologies involving changes in the microbiota, possibly attributable to pathogens such as Mycobacterium avium paratuberculosis and adherent-invasive Escherichia coli [183]. These pathogens can induce an inflammatory response [184186], which may be associated with higher risk of carcinogenesis; however, more studies demonstrating the chronicity of these infections in IBD patients and their potential role in carcinogenesis are needed.

Various murine models of colitis-associated cancer (CAC) [187] have elucidated much of the carcinogenic process, such as a genetic model of IL-10-deficient mice that develop spontaneous colitis and colonic neoplasms [44] and a DSS-induced colitis and carcinoma model. DSS is a mucosal irritant that induces damage similar to that seen in UC patients, and, through a dose-repeated regimen, DSSexposed mice develop tumors [188, 189]. An additional chemically induced murine model involves an azoxymethane $(\mathrm{AOM})$ stimulus combined with repeated DSS doses. AOM is a mutagenic agent favoring mutation of the $\beta$-catenin protooncogene, inducing localization to the nucleus and increasing iNOS and cyclooxygenase (COX-2) expression $[190,191]$. Through the animal models, we have learned that inflammatory cytokines, chemokines, and growth factors play crucial roles in CAC development. However, these models have limitations, as they do not always represent the complexity of the mechanisms involved in CRC-IBD patients [187].

In IBD, many inflammatory cytokines are involved in carcinogenesis, such as TNF- $\alpha$ and IL-6 (Table 2). In untreated UC patients, mucosal TNF- $\alpha$ levels correlate with the degree of swelling [192]. Furthermore, high IL-6 levels have been observed in intestinal biopsies from active IBD patients [193], 
and murine models have demonstrated a crucial role for these two relevant proinflammatory cytokines in the initiation and progression of CAC $[33,194]$.

As noted above, proinflammatory cytokines can induce the generation of RONS, a process that has been observed in IBD patients [115], increasing the risk of carcinogenesis [195] by promoting oxidative stress-mediated DNA damage [19]. High ROS levels induced by chronic inflammation have been associated with early p53 mutations in CAC, distinguishing it from sporadic colorectal cancer, in which these mutations have been identified in later stages of malignancy [196]. Thus, the mutagenic potential of RONS, together with early mutations of the $\mathrm{p} 53$ tumor suppressor gene, has the potential to increase the cumulative risk associated with genetic alterations predisposing to carcinogenesis in UC patients.

There is abundant evidence for the role of EMT in CAC progression and the participation of TGF- $\beta$ in EMT [38]. Patients with IBD or CRC show elevated TGF- $\beta$ levels [197, 198]. In an IL-10-deficient CAC murine model, incidence of colorectal carcinoma was $65 \%$ at the age of $10-31$ weeks, and plasma TGF- $\beta$ levels were higher than in their wild-type littermates [44]. Through in vitro assays, a well-differentiated colon carcinoma cell line LIM1863 was shown to undergo EMT conversion with a migratory monolayer phenotype in response to TGF- $\beta$. Moreover, TNF- $\alpha$ stimulates IL- 8 expression, which in turn accelerates TGF- $\beta$-induced EMT [21]. Therefore, a proinflammatory stimulus favors the invasive properties of CAC, potentiating EMT.

As previously detailed, angiogenesis is a relevant process in carcinogenesis. Mucosal tissue from IBD patients shows higher microvessel density, a process associated with increased expression of VEGF-induced inflammation [22, 199]. Concomitantly, the CAC mouse model replicated the higher VEGF activity, and blockade of VEGFR2 suppressed tumor development, angiogenesis, and cell proliferation [200].

Furthermore, in an experimental murine cancer metastasis model in which tumor growth was stimulated by bacterial lipopolysaccharide (LPS) injection, TNF- $\alpha$-induced NF- $\kappa$ B signaling in tumor cells was essential for the generation of metastasis. Moreover, NF- $\kappa$ B blockade resulted in reversion of LPS-induced tumor growth [20]. Taken together, these effects of NF- $\kappa \mathrm{B}$ signaling indicate that it is a decisive pathway for driving metastasis.

A recently described molecule involved in metastasis is periostin, an extracellular matrix protein secreted in response to mechanical stress and tissue repair by pericryptal and cancer associated fibroblasts (CAFs). Periostin is expressed in invasive front of colon carcinoma, suggesting its participation in tumor growth [201]. Periostin expression dramatically enhances metastatic growth of colon cancer by both preventing stress-induced apoptosis in cancer cells and augmenting endothelial cell survival to promote angiogenesis [202].

The inflammatory process associated with carcinogenesis in CAC is not limited to the above-mentioned cytokines. Other inflammatory mediators are also involved, such as the proinflammatory cytokine IL-17, which was found to be elevated in the mucosa and serum of active IBD patients [203]. Furthermore, IL-17 is overexpressed in tumors from
CAC patients and is associated with angiogenesis and poor prognosis markers [46]. The protumorigenic role of IL-17 has also been observed in a IL-17-deficient mouse model of CAC induced with AOM and DSS, where minor tumor formation and a decrease in proinflammatory markers were found for the IL-17-deficient mice as compared to wild-type mice [204].

Another proinflammatory cytokine with a role in CAC is IL-21, which is elevated in the mucosa of IBD patients and in the CAC mouse model [49]. Furthermore, blockade of the IL-21 signaling pathway reduces tumor development and mucosal microenvironment inflammation [49].

Interferon- $\gamma($ IFN- $\gamma)$ is a proinflammatory cytokine with pleiotropic functions [205]. Increased numbers of IFN- $\gamma$ positive cells have been observed in IBD patients, especially Crohn's disease [27], possibly contributing to a chronic inflammatory setting. Moreover, IFN- $\gamma$-deficient mice did not develop DSS-induced colitis [28]. In early IBD pathogenesis, IFN- $\gamma$ plays an important role in increasing paracellular permeability in T84 epithelial cells by inducing endocytosis of tight-junction (TJ) proteins occludin, JAM-A, and claudin1 [29]. In an IL-10-deficient model, enterocolitis and tumor formation were dependent on the participation of IFN- $\gamma$, as blockage with a neutralizing antibody prevented colitis and cancer in young mice (less than 3 weeks old). However, this effect was not seen in mice older than 3 months, emphasizing the role of IFN- $\gamma$ as an early inducer of inflammation [95].

In an AOM/TNBS-CAC murine model, Osawa et al. showed that IFN- $\gamma^{-1-}$ mice developed higher numbers of tumors than wild-type or IL- $4^{-/-}$mice. This points to the antitumor immune response of IFN- $\gamma$ [30]. In patients with UC-associated cancer and a group of UC patients with chronic severe inflammation, the IFN-inducible gene family $1-8 \mathrm{U}$ was overexpressed. However, the consequences of increased IFN- $\gamma$ expression in UC and its contribution to carcinogenesis remain unclear [31].

Other molecules induced by IFN- $\gamma$ have been also observed in IBD patients, such as IL-18 and IL-18 binding protein (IL-18BP), which have been furthermore associated with inflammation and cancer [32].

Interleukin 8 (IL-8), a member of the neutrophil-specific CXC subfamily of chemokines with the ELR (Glu-LeuArg) motif, acts as a chemoattractant to neutrophils during acute inflammatory response [206]. Increased levels of this chemokine have been reported in IBD patients [207], correlating histologically with areas of active inflammation [208], mainly associated with neutrophils and macrophages [209]. Additionally, colon cancer cells also express IL-8 [210]; in sporadic cancer, higher levels of this cytokine were observed in tissue from moderately and poorly differentiated as compared to well-differentiated tumors [211]. In addition, IL-8 levels are directly correlated with metastatic potential in colon cancer cell lines [210]. Overexpression of IL-8 in HCT116 and Caco2 cell lines results in increased proliferation, cell migration, and invasion, while in a tumor xenograft model, IL-8-overexpressing cells formed larger tumors and showed higher microvessel density [41]. This in vivo effect of IL-8 on angiogenesis is supported by a study using primary cultures of human intestinal microvascular endothelial cells, 
TABLE 2: Significance and role of cytokines in tumorigenesis.

\begin{tabular}{lll}
\hline Cytokines & Colitis-associated cancer (references) & CCA (references) \\
\hline & $\begin{array}{l}\text { Tumor-promoting role in various stages } \\
\text { of carcinogenesis. Related to RONS } \\
\text { generation in IBD patients, promoting } \\
\text { oxidative stress-mediated DNA damage. }\end{array}$ & $\begin{array}{l}\text { Essential for bile duct epithelial cell } \\
\text { proliferation. Impairs epithelial barrier } \\
\text { function. Disrupts cholangiocyte } \\
\text { tight-junction and influences the } \\
\text { aggravation of bile duct cholestasis. }\end{array}$ \\
Stimulates TGF- $\beta$-induced EMT. Induces \\
secretion of VEGF by human fibroblasts, \\
promoting angiogenesis. Induces NF- $\kappa$ B \\
signaling, a decisive pathway in driving \\
metastasis in a model of CAC [19-22].
\end{tabular}

Increases in IFN- $\gamma^{+}$cells have been observed in IBD patients. Deficient mice did not develop DSS-induced colitis. Increases paracellular permeability in early IBD pathogenesis. Deficient mice developed higher numbers of tumors, suggesting an antitumor immune IFN- $\gamma \quad$ response of IFN- $\gamma$. In patients with UC-associated cancer and a group of UC patients with chronic severe inflammation, the IFN-inducible gene family $1-8 \mathrm{U}$ was overexpressed. Induces IL-18 and IL-18 binding protein (IL-18BP) in IBD, which have been also associated with inflammation and cancer [27-32].

Induces oxidative stress. A critical tumor promoter during early CAC

IL-6 tumorigenesis. TAM-derived IL-6 contributes to CAC in animal models. CRC patients present with high levels of IL-6 and VEGF [19, 33-35].

Induces CAC progression, promoting EMT. In later stages of carcinogenesis, it TGF- $\beta$ promotes tumor growth by creating an immunotolerant tumor environment $[38,39]$.

Colon cancer cell lines overexpressing IL-8 show enhanced proliferation, IL-8 migration, and angiogenesis. IL-8 induced by TNF- $\alpha$ accelerates EMT $[21,41]$.

IL-10 $0^{-/-}$mice develop colitis and

IL-10 colorectal cancer, similar to IBD-associated cancer in humans [44].

Overexpressed in tumors from CAC patients and is associated with

IL-17 angiogenesis and poor prognosis markers. Secreted in tumors by macrophages/monocytes CD68+; Th17 and Treg FOXP3 ${ }^{+} \mathrm{IL}^{+}{ }^{+}$cells $[46,47]$.
Reduces transepithelial electrical resistance. Alters cholangiocyte tight-junction, leading to aggravation of bile duct cholestasis [24].
Cholangiocyte and CCA cells can be activated by proinflammatory cytokines through the NF- $\kappa \mathrm{B}$-dependent pathway, leading to overproduction of bile duct epithelium growth factor, thus promoting cancer initiation and progression [36, 37].

Promotes proliferation of bile duct epithelial cells and induces

EMT-mediated tumor aggressiveness $[23,40]$.

Secreted by cholangiocytes in response to proinflammatory cytokines and together with MCP-1 and CCL-28 promotes leukocyte adhesion and retention in injured biliary epithelial cells. Injured cholangiocytes then release IGF-1 and VEGF, which can stimulate CCA cell growth $[42,43]$.

CCA can activate macrophage polarization into M2 phenotype through the STAT-3 pathway, leading to IL-10, VEGF-A, TGF- $\beta$, and MMP-2 production [45].

Tumor-infiltrating lymphocytes IL-17 are found in CCA intratumoral areas and correlate with lymph node metastasis, intrahepatic metastasis, and advanced stages [48]. 
TABLE 2: Continued.

\begin{tabular}{lll}
\hline Cytokines & Colitis-associated cancer (references) & CCA (references) \\
\hline & Enhanced in mucosa of IBD patients and & \\
iL-21 & in the CAC mouse model. Blockade of & No available references for this cytokine \\
& IL-21 signaling reduces tumor & in CCA. \\
& development and mucosal & \\
\hline
\end{tabular}

which respond to IL- 8 through the CXCR2 receptor, eliciting an angiogenic response [212].

These findings illustrate the complex role of cytokines in the various events associated with the development of CAC. Therefore, controlling the inflammatory process early in IBD is important for reducing risk of colorectal cancer.

\section{Primary Sclerosing Cholangitis- (PSC-) and Liver Fluke-Associated Cholangiocarcinoma (CCA)}

CCA is a malignant neoplasm originating from the epithelial cells lining the intra- or extrahepatic biliary ducts. It is the second-most frequent liver cancer worldwide, after hepatocellular carcinoma. Five-year survival is about $10 \%$. In the United States, incidence of CCA in the Hispanic population is 2.8 per 100,000; in Asians, 3.3 per 100,000; and in nonHispanic Caucasians and African-Americans, 2.1 per 100,000 [213]. However, incidence varies widely, from the highest reported rate of 113 per 100,000 in the Khon Kaen province of Thailand to as low as 0.1 per 100,000 in Australia [214, 215].

There are several factors that increase the risk for CCA, including primary sclerosing cholangitis, parasitic infection, biliary-duct cysts, hepatolithiasis, viral infection, and toxins $[23,216]$. Primary sclerosing cholangitis (PSC) is characterized by inflammation and fibrosis of biliary ducts leading to biliary tract stricture. The cumulative lifetime incidence of CCA in PSC is around 20\% [217]. More than 50\% of patients with PSC develop CCA simultaneously or within 1 year of diagnosis [218]. The incidence of CCA after PSC diagnosis has been reported in several studies at around $0.5-1.5 \%$ per year [217-219]. CCA must be suspected in any new PSC patient presenting with jaundice, suggesting chronic inflammation of the bile duct.

Opisthorchis viverrini (O. viverrini) and Clonorchis sinensis (C. sinensis) have been classified by the International Agency for Research on Cancer (IARC) as Group I (carcinogenic in humans) [220] and as the most common risk factors for CCA, especially in East and Southeast Asia [221, 222]. The high incidence of $O$. viverrini infection, which is due to the custom of eating raw fish containing the infectious stage of the parasites, was found to be correlated with the high prevalence of CCA in the northeastern part of Thailand [221]. PSC, hepatolithiasis, and choledochal cysts are the risk factors for CCA in areas where liver fluke is not endemic in Thailand [215]. In addition, biliary ascariasis caused by Ascaris lumbricoides infection in China, India, and some areas of South America has also been reported in association with CCA development [223, 224].
Infection with hepatitis viruses can generate hepatocellular carcinomas, especially hepatitis B, in which more than $80 \%$ of cases develop cancer [225]. It is becoming more accepted that both hepatitis $B$ and hepatitis $C$ viruses may be associated with biliary inflammation and can cause CCA. Approximately $13.8 \%$ and $1.9 \%$ of CCA patients have positive findings for hepatitis B and hepatitis C, respectively [226].

Other etiologies that may or may not cause bile duct obstruction but result in the chronic inflammation of biliary epithelial cells are proposed CCA risk factors, including gallstone formation, choledochoenteric anastomosis, and chemical and radiation exposure [23].

CCA, like many other cancers in that its carcinogenesis is a multistep process, requires interaction between mutated biliary epithelial cells and environmental factors. Many hallmarks of cancer have been proposed, and the list has been continually updated over the years [7]. The genes involved in controlling these properties have been found to be mutated in cancer patients. In CCA, several protooncogenes including K-ras [227-229], c-erbB-2, and c-Met [230]; tumor suppressor genes, that is, p53; and antiapoptotic genes such as $\mathrm{Bcl}-2, \mathrm{Bcl}-\mathrm{X}(\mathrm{L})$, and $\mathrm{Mcl}-1$ [231] are mutated. In PSCmediated CCA, the mutation was detected in the promoter, leading to the overexpression of p16INK4a and p14ARF cell cycle regulators [232].

During the genesis of CCA, both PSC and parasitic infections cause cholestasis and chronic inflammation of the bile duct, which can induce the epithelial cells to produce a variety of cytokines including IL-6, IL-8, TGF- $\beta$, TNF- $\alpha$, plateletderived growth factor (PDGF), and epidermal growth factor (EGF) (Table 2) [23]. The release of IL-6, TGF- $\beta$, TNF- $\alpha$, and PDGFA is essential for bile duct epithelial cell proliferation. The production of PDGFA and the overexpression of its receptors during cholangiocarcinogenesis in O. viverriniinfected hamsters indicate the potential of these molecules to downregulate many antiproliferative factors and promote the angiogenesis pathway [233]. In addition, PDGFA expression in CCA tissue and serum is correlated with patient survival time and has been proposed as a marker of poor prognosis [234].

TNF- $\alpha$ and IFN- $\gamma$, which are cytokines released during chronic inflammation, can cause alteration of biliary barrier function [24], whereas proinflammatory cytokines alter cholangiocyte choleretic activity $[42,43]$. When cholangiocytes are exposed to these cytokines, they respond by secreting other molecules such as IL-8, MCP-1, and CCL28 that can promote leukocyte adhesion and retention at the site of inflammation, leading to more damage of biliary cells. The injured cholangiocytes can release insulin-like growth 
factor-1 (IGF-1) and VEGF to stimulate CCA cell growth and angiogenesis, respectively [235-238].

TNF- $\alpha$ can activate increased expression of AID (activation-induced cytidine deaminase, a member of the DNA/RNA-editing enzyme family) in CCA-derived cells, but not in PSC-derived epithelial cells [25]. AID results in the generation of somatic mutations of many tumor-related genes, including p53, c-Myc, and CDKN2A (or INK4A/p16) promoter sequences. This finding suggests a connection between chronic inflammation and tumorigenesis via the mutagenic activity of AID [25]. In addition, NF$\kappa \mathrm{B}$ activation in cells by chronic inflammation-derived cytokines might lead to the activation of active transcription factors translocating into the nucleus and regulating the expression of IL-6, TNF- $\alpha$, and several growth factors which can change the microenvironment for tumor promotion [36]. Moreover, the release of nitric oxide with the formation of 3-nitrotyrosine and other reactive oxidants can inhibit the DNA-repair process, which allows for oxidative DNA damage to cells and thus promotes tumor formation [239].

Cholangiocytes and CCA cells do not act alone but are surrounded by several types of cells, generally known as microenvironmental cells. Fibroblasts are the main microenvironmental cells, and their function in stimulating the acquired hallmark capabilities of cancer cells is well-known [240]. Activated CCA-associated fibroblast phenotypes were found to show increased expression of $\alpha$-SMA [241]. Interestingly, these fibroblasts were isolated from CCA tissues obtained from patients and mapped for the specific gene expression pattern resulting in the expression of several cancer-promoting proteins [242]. Researchers have since identified several substances that can be produced by CCAassociated fibroblasts, including periostin, hepatocyte growth factor (HGF), tenascin-C, and CXCL-12 [243, 244]. Interestingly, these soluble factors are involved in several tumorigenic properties leading to the progression and metastasis of the cancer. These findings suggest that fibroblasts, their secreting products, and the activated pathways in the cancer cells could be promising targets for attenuation of disease progression $[243,245]$.

Many immune cells are known to surround cancer cells, with detrimental or beneficial effects on cancer progression, depending on the profile of substances secreted into the tumor microenvironment. The substances secreted from CCA cells were studied in vitro with human macrophages, and the results exhibited M2 polarization of macrophages as well as overproduction of cytokines and other bioactive molecules, including IL-10, VEGF-A, TGF- $\beta$, and matrix metalloproteinase- (MMP-) 2 [45]. In intrahepatic CCA, the tumor-infiltrating lymphocytes IL-17 $7^{+}$and FOXP3 ${ }^{+}, \mathrm{CD} 6 \mathrm{~b}^{+}$ neutrophils, and microvessels were predominantly found in the intratumor area, whereas $\mathrm{CD} 8^{+}$lymphocytes were most abundant in the tumor invasive front [48]. Although IL-17 levels have never been reported for CCA, this study suggested for the first time that intratumor $\mathrm{IL}-17^{+}$lymphocytes and neutrophils could be used as a marker of poor prognosis in CCA.

TGF- $\beta$ was studied with CCA cell lines, and the results demonstrated the potential of TGF- $\beta$ to induce
EMT-mediated cancer progression via the Snail transcription factor, leading to increasing levels of vimentin, S100A4, collagen type 1, and MMP-2 production [40]. EMT level is closely associated with aggressiveness of the disease and could be proposed as a marker of poor prognosis. Moreover, TNF- $\alpha$ has been recently reported to have the ability to induce EMT of CCA cells [26].

In conclusion, the chronic inflammation-driven cytokines released from biliary cells, fibroblasts, or immune cells into the microenvironment of the bile duct epithelium may facilitate cell immortalization, evasion of apoptosis, and autonomous proliferation in untransformed cells, leading to the development of CCA [23]. In addition, cytokines may help activate invasion, metastasis, and EMT-mediated CCA progression.

\section{Conclusion}

The tumor microenvironment formed by stromal cells, infiltrating immune cells, and tumor cells contains factors that can promote carcinogenesis. Ample evidence supports the involvement of cytokines in events leading to the initiation, promotion, invasion, and metastasis of cancer (Figure 1). In a chronic inflammatory process, cytokines such as TNF$\alpha$ and IL- 6 induce the generation of free radicals that can damage DNA, potentially causing mutations that lead to tumor initiation. Tumor growth is also favored by proinflammatory cytokines that stimulate cell proliferation and reduce apoptosis, while anti-inflammatory cytokines, such as IL-10 and TGF- $\beta$, contribute to tumor immune evasion. The invasive properties of tumors are related to the activation of the epithelial-mesenchymal transition program triggered by TGF- $\beta$ and enhanced by proinflammatory cytokines, such as TNF- $\alpha$ and IL-6. Proinflammatory cytokines also play an important role in angiogenesis and metastasis. In the latter, chemokines such as IL-8 have an important role in cell migration to other tissues.

Although we observed that many cytokines contribute to carcinogenesis, their pro- or antitumoral roles depend on the balance of these different inflammatory mediators and the stage of tumor development. For this reason, studying the role of these mediators in different tumors or stages of development is essential for designing new personalized treatments using these potential therapeutic targets.

In this line, the potential role of cytokines has been reported, as a diagnostic marker for cancer. The determination of the serum levels of cytokines, such as IL- 6 or IL10 , might be associated with a tumorigenic process or poor prognosis $[69,105]$. However, further prospective studies are needed to determine trusted cut-off values of circulating cytokine to establish a direct relationship with cancer.

In the field of therapy, several clinical trials have been implemented in order to evaluate inhibitors of cytokines receptors or neutralizing antibodies that prevent the sustained exposure to these inflammatory mediators that promote tumor progression $[80,103]$. On the other hand, from the findings of Coley [56], who associates an infectious process with the control of tumor progression, arises 
the idea to cause an acute inflammation to activate antitumor response mechanisms [58].

While progress has been made in the understanding of the mechanisms of these cytokines in the tumorigenic process, establishing a relationship between cytokines expression and disease progression, survival, and response to therapy remains a major challenge.

\section{Conflict of Interests}

The authors declare that there is no conflict of interests regarding the publication of this paper.

\section{Authors' Contribution}

Glauben Landskron and Marjorie De la Fuente are contributed equally to this paper.

\section{Acknowledgments}

The figures were produced using Servier Medical Art from www.servier.com. Funding was received from FONDECYT 1120577 (MAH) and CONICYT REDES130037 (MAH).

\section{References}

[1] R. Virchow, Die Krankhaften Geschwülste, Berlin, Germany, 1863.

[2] F. Balkwill and A. Mantovani, "Inflammation and cancer: back to Virchow?" The Lancet, vol. 357, no. 9255, pp. 539-545, 2001.

[3] S. P. Hussain and C. C. Harris, "Inflammation and cancer: an ancient link with novel potentials," International Journal of Cancer, vol. 121, no. 11, pp. 2373-2380, 2007.

[4] L. Yan, G. M. Anderson, M. DeWitte, and M. T. Nakada, "Therapeutic potential of cytokine and chemokine antagonists in cancer therapy," European Journal of Cancer, vol. 42, no. 6, pp. 793-802, 2006.

[5] R. Medzhitov, "Origin and physiological roles of inflammation," Nature, vol. 454, no. 7203, pp. 428-435, 2008.

[6] L. V. Norling and C. N. Serhan, "Profiling in resolving inflammatory exudates identifies novel anti-inflammatory and proresolving mediators and signals for termination," Journal of Internal Medicine, vol. 268, no. 1, pp. 15-24, 2010.

[7] D. Hanahan and R. A. Weinberg, "Hallmarks of cancer: the next generation," Cell, vol. 144, no. 5, pp. 646-674, 2011.

[8] T. Jess, E. V. Loftus Jr., F. S. Velayos et al., "Risk of intestinal cancer in inflammatory bowel disease: a population-based study from olmsted county, Minnesota," Gastroenterology, vol. 130, no. 4, pp. 1039-1046, 2006.

[9] A. Zabron, R. J. Edwards, and S. Khan, "The challenge of cholangiocarcinoma: dissecting the molecular mechanisms of an insidious cancer," Disease Models \& Mechanisms, vol. 6, no. 2, pp. 281-292, 2013.

[10] T. Yoshida, J. Kato, I. Inoue et al., "Cancer development based on chronic active gastritis and resulting gastric atrophy as assessed by serum levels of pepsinogen and Helicobacter pylori antibody titer," International Journal of Cancer, vol. 134, no. 6, pp. 14451457, 2014.

[11] H. Vainio and P. Boffetta, "Mechanisms of the combined effect of asbestos and smoking in the etiology of lung cancer,"
Scandinavian Journal of Work, Environment and Health, vol. 20, no. 4, pp. 235-242, 1994.

[12] J. N. Krieger, D. E. Riley, R. L. Vesella, D. C. Miner, S. O. Ross, and P. H. Lange, "Bacterial DNA sequences in prostate tissue from patients with prostate cancer and chronic prostatitis," Journal of Urology, vol. 164, no. 4, pp. 1221-1228, 2000.

[13] H. B. El-Serag, "Epidemiology of viral hepatitis and hepatocellular carcinoma," Gastroenterology, vol. 142, no. 6, pp. 12641273, 2012.

[14] R. K. Singh, M. Gutman, R. Reich, and M. Bar-Eli, "Ultraviolet B irradiation promotes tumorigenic and metastatic properties in primary cutaneous melanoma via induction of interleukin 8," Cancer Research, vol. 55, no. 16, pp. 3669-3674, 1995.

[15] A. S. Bats, Y. Zafrani, P. Pautier, P. Duvillard, and P. Morice, "Malignant transformation of abdominal wall endometriosis to clear cell carcinoma: case report and review of the literature," Fertility and Sterility, vol. 90, no. 4, pp. 1197.e13-1197.e16, 2008.

[16] J. G. Fox, F. E. Dewhirst, Z. Shen et al., "Hepatic Helicobacter species identified in bile and gallbladder tissue from Chileans with chronic cholecystitis," Gastroenterology, vol. 114, no. 4 I, pp. 755-763, 1998.

[17] B. Levin, "Gallbladder carcinoma," Annals of Oncology, vol. 10, no. 4, pp. S129-S130, 1999.

[18] A. J. Cameron and H. A. Carpenter, "Barrett's esophagus, high-grade dysplasia, and early adenocarcinoma: a pathological study," American Journal of Gastroenterology, vol. 92, no. 4, pp. 586-591, 1997.

[19] M. Murata, R. Thanan, N. Ma, and S. Kawanishi, "Role of nitrative and oxidative DNA damage in inflammation-related carcinogenesis," Journal of Biomedicine and Biotechnology, vol. 2012, Article ID 623019, 11 pages, 2012.

[20] J.-L. Luo, S. Maeda, L.-C. Hsu, H. Yagita, and M. Karin, "Inhibition of NF- $\kappa \mathrm{B}$ in cancer cells converts inflammationinduced tumor growth mediated by TNF $\alpha$ to TRAIL-mediated tumor regression," Cancer Cell, vol. 6, no. 3, pp. 297-305, 2004.

[21] R. C. Bates and A. M. Mercurio, "Tumor necrosis factor- $\alpha$ stimulates the epithelial-tomesenchymal transition of human colonic organoids," Molecular Biology of the Cell, vol. 14, no. 5, pp. 1790-1800, 2003.

[22] S. Danese, M. Sans, C. de la Motte et al., "Angiogenesis as a novel component of inflammatory bowel disease pathogenesis," Gastroenterology, vol. 130, no. 7, pp. 2060-2073, 2006.

[23] R. Al-Bahrani, Y. Abuetabh, N. Zeitouni, and C. Sergi, "Cholangiocarcinoma: risk factors, environmental influences and oncogenesis," Annals of Clinical \& Laboratory Science, vol. 43, no. 2, pp. 195-210, 2013.

[24] S. Hanada, M. Harada, H. Koga et al., "Tumor necrosis factor- $\alpha$ and interferon- $\gamma$ directly impair epithelial barrier function in cultured moused cholangiocytes," Liver International, vol. 23, no. 1, pp. 3-11, 2003.

[25] J. Komori, H. Marusawa, T. Machimoto et al., "Activationinduced cytidine deaminase links bile duct inflammation to human cholangiocarcinoma," Hepatology, vol. 47, no. 3, pp. 888896, 2008.

[26] A. Techasen, N. Namwat, W. Loilome et al., "Tumor necrosis factor- $\alpha$ (TNF- $\alpha$ ) stimulates the epithelial-mesenchymal transition regulator Snail in cholangiocarcinoma," Medical Oncology, vol. 29, no. 5, pp. 3083-3091, 2012.

[27] L. Camoglio, A. A. Te Velde, A. J. Tigges, P. K. Das, and S. J. H. Van Deventer, "Altered expression of interferon- $\gamma$ and interleukin-4 in inflammatory bowel disease," Inflammatory Bowel Diseases, vol. 4, no. 4, pp. 285-290, 1998. 
[28] R. Ito, M. Shin-Ya, T. Kishida et al., "Interferon-gamma is causatively involved in experimental inflammatory bowel disease in mice," Clinical and Experimental Immunology, vol. 146, no. 2, pp. 330-338, 2006.

[29] M. Bruewer, A. Luegering, T. Kucharzik et al., "Proinflammatory cytokines disrupt epithelial barrier function by apoptosisindependent mechanisms," Journal of Immunology, vol. 171, no. 11, pp. 6164-6172, 2003.

[30] E. Osawa, A. Nakajima, T. Fujisawa et al., "Predominant T helper type 2-inflammatory responses promote murine colon cancers," International Journal of Cancer, vol. 118, no. 9, pp. 2232-2236, 2006.

[31] T. Hisamatsu, M. Watanabe, H. Ogata et al., "Interferoninducible gene family $1-8 \mathrm{U}$ expression in colitis-associated colon cancer and severely inflamed mucosa in ulcerative colitis," Cancer Research, vol. 59, no. 23, pp. 5927-5931, 1999.

[32] J. Paulukat, M. Bosmann, M. Nold et al., "Expression and release of IL-18 binding protein in response to IFN- $\gamma$," Journal of Immunology, vol. 167, no. 12, pp. 7038-7043, 2001.

[33] S. Matsumoto, T. Hara, K. Mitsuyama et al., "Essential roles of IL- 6 trans-signaling in colonic epithelial cells, induced by the IL-6/soluble-IL-6 receptor derived from lamina propria macrophages, on the development of colitis-associated premalignant cancer in a murine model," Journal of Immunology, vol. 184, no. 3, pp. 1543-1551, 2010.

[34] S. Grivennikov, E. Karin, J. Terzic et al., "IL-6 and Stat3 are required for survival of intestinal epithelial cells and development of colitis-associated cancer," Cancer Cell, vol. 15, no. 2, pp. 103-113, 2009.

[35] K. Middleton, J. Jones, Z. Lwin, and J. I. G. Coward, "Interleukin-6: an angiogenic target in solid tumours," Critical Reviews in Oncology/Hematology, vol. 89, no. 1, pp. 129-139, 2014.

[36] A. M. Elsharkawy and D. A. Mann, "Nuclear factor- $\kappa$ B and the hepatic inflammation-fibrosis-cancer axis," Hepatology, vol. 46, no. 2, pp. 590-597, 2007.

[37] F. Meng, H. Wehbe-Janek, R. Henson, H. Smith, and T. Patel, "Epigenetic regulation of microRNA-370 by interleukin- 6 in malignant human cholangiocytes," Oncogene, vol. 27, no. 3, pp. 378-386, 2008.

[38] R. C. Bates and A. M. Mercurio, "The epithelial-mesenchymal transition (EMT) and colorectal cancer progression," Cancer Biology and Therapy, vol. 4, no. 4, pp. 365-370, 2005.

[39] L. A. Feagins, "Role of transforming growth factor- $\beta$ in inflammatory bowel disease and colitis-associated colon cancer," Inflammatory Bowel Diseases, vol. 16, no. 11, pp. 1963-1968, 2010.

[40] Y. Sato, K. Harada, K. Itatsu et al., "Epithelial-mesenchymal transition induced by transforming growth factor- $\beta 1 /$ snail activation aggravates invasive growth of cholangiocarcinoma," American Journal of Pathology, vol. 177, no. 1, pp. 141-152, 2010.

[41] Y. Ning, P. C. Manegold, Y. K. Hong et al., "Interleukin-8 is associated with proliferation, migration, angiogenesis and chemosensitivity in vitro and in vivo in colon cancer cell line models," International Journal of Cancer, vol. 128, no. 9, pp. 2038-2049, 2011.

[42] C. Spirlì, L. Fabris, E. Duner et al., "Cytokine-stimulated nitric oxide production inhibits adenylyl cyclase and cAMPdependent secretion in cholangiocytes," Gastroenterology, vol. 124, no. 3, pp. 737-753, 2003.

[43] C. Spiral, M. H. Nathanson, R. Fiorotto et al., "Proinflammatory cytokines inhibit secretion in rat bile duct epithelium," Gastroenterology, vol. 121, no. 1, pp. 156-169, 2001.
[44] S. Sturlan, G. Oberhuber, B. G. Beinhauer et al., "Interleukin10 -deficient mice and inflammatory bowel disease associated cancer development," Carcinogenesis, vol. 22, no. 4, pp. 665-671, 2001.

[45] H. Hasita, Y. Komohara, H. Okabe et al., "Significance of alternatively activated macrophages in patients with intrahepatic cholangiocarcinoma," Cancer Science, vol. 101, no. 8, pp. 19131919, 2010.

[46] J. Liu, Y. Duan, X. Cheng et al., "IL-17 is associated with poor prognosis and promotes angiogenesis via stimulating VEGF production of cancer cells in colorectal carcinoma," Biochemical and Biophysical Research Communications, vol. 407, no. 2, pp. 348-354, 2011.

[47] E. Gounaris, N. R. Blatner, K. Dennis et al., "T-regulatory cells shift from a protective anti-inflammatory to a cancerpromoting proinflammatory phenotype in polyposis," Cancer Research, vol. 69, no. 13, pp. 5490-5497, 2009.

[48] F.-M. Gu, Q. Gao, G.-M. Shi et al., "Intratumoral IL-17+ cells and neutrophils show strong prognostic significance in intrahepatic cholangiocarcinoma," Annals of Surgical Oncology, vol. 19, no. 8, pp. 2506-2514, 2012.

[49] C. Stolfi, A. Rizzo, E. Franzè et al., "Involvement of interleukin21 in the regulation of colitis-associated colon cancer," Journal of Experimental Medicine, vol. 208, no. 11, pp. 2279-2290, 2011.

[50] B. F. Zamarron and W. Chen, "Dual roles of immune cells and their factors in cancer development and progression," International Journal of Biological Sciences, vol. 7, no. 5, pp. 651658, 2011.

[51] C. Popa, M. G. Netea, P. L. C. M. Van Riel, J. W. M. Van Der Meer, and A. F. H. Stalenhoef, "The role of TNF- $\alpha$ in chronic inflammatory conditions, intermediary metabolism, and cardiovascular risk," Journal of Lipid Research, vol. 48, no. 4, pp. 751-762, 2007.

[52] R. J. Moore, D. M. Owens, G. Stamp et al., "Mice deficient in tumor necrosis factor-alpha are resistant to skin carcinogenesis," Nature Medicine, vol. 5, no. 7, pp. 828-831, 1999.

[53] P. Szlosarek, K. A. Charles, and F. R. Balkwill, "Tumour necrosis factor- $\alpha$ as a tumour promoter," European Journal of Cancer, vol. 42, no. 6, pp. 745-750, 2006.

[54] G. Chen and D. V. Goeddel, "TNF-R1 signaling: a beautiful pathway," Science, vol. 296, no. 5573, pp. 1634-1635, 2002.

[55] E. A. Havell, W. Fiers, and R. J. North, "The antitumor function of tumor necrosis factor (TNF)-I. Therapeutic action of TNF against an established murine sarcoma is indirect, immunologically dependent, and limited by severe toxicity," Journal of Experimental Medicine, vol. 167, no. 3, pp. 1067-1085, 1988.

[56] B. Wiemann and C. O. Starnes, "Coley's toxins, tumor necrosis factor and cancer research: a historical perspective," Pharmacology and Therapeutics, vol. 64, no. 3, pp. 529-564, 1994.

[57] F. J. Lejeune, C. Rüegg, and D. Liénard, "Clinical applications of TNF-alpha in cancer," Current Opinion in Immunology, vol. 10, no. 5, pp. 573-580, 1998.

[58] J. M. Herman, A. T. Wild, H. Wang et al., "Randomized phase III multi-institutional study of TNFerade biologic with fluorouracil and radiotherapy for locally advanced pancreatic cancer: final results," Journal of Clinical Oncology, vol. 31, no. 7, pp. 886-894, 2013.

[59] K. J. Chang, T. Reid, N. Senzer et al., "Phase I evaluation of TNFerade Biologic plus chemoradiotherapy before esophagectomy for locally advanced resectable esophageal cancer," Gastrointestinal Endoscopy, vol. 75, pp. 1139-1146, 2012. 
[60] G. M. Anderson, M. T. Nakada, and M. DeWitte, "Tumor necrosis factor- $\alpha$ in the pathogenesis and treatment of cancer," Current Opinion in Pharmacology, vol. 4, no. 4, pp. 314-320, 2004.

[61] F. Balkwill, "TNF- $\alpha$ in promotion and progression of cancer," Cancer and Metastasis Reviews, vol. 25, no. 3, pp. 409-416, 2006.

[62] C.-H. Woo, Y.-W. Eom, M.-H. Yoo et al., "Tumor necrosis factor- $\alpha$ generates reactive oxygen species via a cytosolic phospholipase A2-linked cascade," Journal of Biological Chemistry, vol. 275, no. 41, pp. 32357-32362, 2000.

[63] S. P. Hussain, L. J. Hofseth, and C. C. Harris, "Radical causes of cancer," Nature Reviews Cancer, vol. 3, no. 4, pp. 276-285, 2003.

[64] L. A. Noach, N. B. Bosma, J. Jansen, F. J. Hoek, S. J. H. Van Deventer, and G. N. J. Tytgat, "Mucosal tumor necrosis factor$\alpha$ interleukin- $1 \beta$, and interleukin- 8 production in patients with helicobacter pylori infection," Scandinavian Journal of Gastroenterology, vol. 29, no. 5, pp. 425-429, 1994.

[65] M. Suganuma, T. Watanabe, K. Yamaguchi, A. Takahashi, and H. Fujiki, "Human gastric cancer development with TNF- $\alpha$ inducing protein secreted from Helicobacter pylori," Cancer Letters, vol. 322, no. 2, pp. 133-138, 2012.

[66] J. Kwong, L. C. Franky, K.-K. Wong et al., "Inflammatory cytokine tumor necrosis factor $\alpha$ confers precancerous phenotype in an organoid model of normal human ovarian surface epithelial cells," Neoplasia, vol. 11, no. 6, pp. 529-541, 2009.

[67] C. M. Ohri, A. Shikotra, R. H. Green, D. A. Waller, and P. Bradding, "Tumour necrosis factor-alpha expression in tumour islets confers a survival advantage in non-small cell lung cancer," BMC Cancer, vol. 10, article 323, 2010.

[68] S. H. Lee, H. S. Hong, Z. X. Liu et al., "TNF $\alpha$ enhances cancer stem cell-like phenotype via Notch-Hesl activation in oral squamous cell carcinoma cells," Biochemical and Biophysical Research Communications, vol. 424, no. 1, pp. 58-64, 2012.

[69] K. Heikkilä, S. Ebrahim, and D. A. Lawlor, "Systematic review of the association between circulating interleukin-6 (IL-6) and cancer," European Journal of Cancer, vol. 44, no. 7, pp. 937-945, 2008.

[70] D. R. Hodge, E. M. Hurt, and W. L. Farrar, "The role of IL-6 and STAT3 in inflammation and cancer," European Journal of Cancer, vol. 41, no. 16, pp. 2502-2512, 2005.

[71] J. A. Gasche, J. Hoffmann, C. R. Boland, and A. Goel, "Interleukin-6 promotes tumorigenesis by altering DNA methylation in oral cancer cells," International Journal of Cancer, vol. 129, no. 5, pp. 1053-1063, 2011.

[72] H. Kinoshita, Y. Hirata, H. Nakagawa et al., "Interleukin-6 mediates epithelial-stromal interactions and promotes gastric tumorigenesis," PLoS ONE, vol. 8, no. 4, Article ID e60914, 2013.

[73] M. Chatterjee, T. Stühmer, P. Herrmann, K. Bommert, B. Dörken, and R. C. Bargou, "Combined disruption of both the MEK/ERK and the IL-6R/STAT3 pathways is required to induce apoptosis of multiple myeloma cells in the presence of bone marrow stromal cells," Blood, vol. 104, no. 12, pp. 3712-3721, 2004.

[74] D. M. Hilbert, M. Kopf, B. A. Mock, G. Köhler, and S. Rudikoff, "Interleukin 6 is essential for in vivo development of B lineage neoplasms," Journal of Experimental Medicine, vol. 182, no. 1, pp. 243-248, 1995.

[75] S.-Y. Kim, J. W. Kang, X. Song et al., "Role of the IL-6-JAK1STAT3-Oct-4 pathway in the conversion of non-stem cancer cells into cancer stem-like cells," Cell Signaling, vol. 25, no. 4, pp. 961-969, 2013.
[76] L. Song, B. Rawal, J. A. Nemeth, and E. B. Haura, "JAK1 activates STAT3 activity in non-small-cell lung cancer cells and IL-6 neutralizing antibodies can suppress JAK1-STAT3 signaling," Molecular Cancer Therapeutics, vol. 10, no. 3, pp. 481-494, 2011.

[77] J. Coward, H. Kulbe, P. Chakravarty et al., "Interleukin-6 as a therapeutic target in human ovarian cancer," Clinical Cancer Research, vol. 17, no. 18, pp. 6083-6096, 2011.

[78] R. Kurzrock, P. M. Voorhees, C. Casper et al., "A phase I, open-label study of siltuximab, an anti-IL-6 monoclonal antibody, in patients with B-cell non-Hodgkin lymphoma, multiple myeloma, or Castleman disease," Clinical Cancer Research, vol. 19, no. 13, pp. 3659-3670, 2013.

[79] J.-F. Rossi, S. Négrier, N. D. James et al., "A phase I/II study of siltuximab (CNTO 328), an anti-interleukin-6 monoclonal antibody, in metastatic renal cell cancer," British Journal of Cancer, vol. 103, no. 8, pp. 1154-1162, 2010.

[80] T. B. Dorff, B. Goldman, J. K. Pinski et al., "Clinical and correlative results of SWOG S0354: a phase II trial of CNTO328 (siltuximab), a monoclonal antibody against interleukin-6, in chemotherapy-pretreated patients with castration-resistant prostate cancer," Clinical Cancer Research, vol. 16, no. 11, pp. 3028-3034, 2010.

[81] J. F. Santibañez, M. Quintanilla, and C. Bernabeu, "TGF$\beta /$ TGF- $\beta$ receptor system and its role in physiological and pathological conditions," Clinical Science, vol. 121, no. 6, pp. 233251, 2011.

[82] J. Massagué, “TGFbeta in cancer," Cell, vol. 134, no. 2, pp. $215-$ 230, 2008.

[83] K. Matsuzaki, "Smad phospho-isoforms direct contextdependent TGF- $\beta$ signaling," Cytokine \& Growth Factor Reviews, vol. 24, no. 4, pp. 385-399, 2013.

[84] C. D. Morrison, J. G. Parvani, and W. P. Schiemann, "The relevance of the TGF- $\beta$ Paradox to EMT-MET programs," Cancer Letters, vol. 341, no. 1, pp. 30-40, 2013.

[85] A. Malliri, W. Andrew Yeudall, M. Nikolic, D. H. Crouch, E. Kenneth Parkinson, and B. Ozanne, "Sensitivity to transforming growth factor $\beta 1$-induced growth arrest is common in human squamous cell carcinoma cell lines: c-MYC downregulation and p21(wafl) induction are important early events," Cell Growth and Differentiation, vol. 7, no. 10, pp. 1291-1304, 1996.

[86] G. Guasch, M. Schober, H. A. Pasolli, E. B. Conn, L. Polak, and E. Fuchs, "Loss of TGF\& signaling destabilizes homeostasis and promotes squamous cell carcinomas in stratified epithelia," Cancer Cell, vol. 12, no. 4, pp. 313-327, 2007.

[87] B. Bierie and H. L. Moses, "TGF- $\beta$ and cancer," Cytokine and Growth Factor Reviews, vol. 17, no. 1-2, pp. 29-40, 2006.

[88] L. Levy and C. S. Hill, "Alterations in components of the TGF- $\beta$ superfamily signaling pathways in human cancer," Cytokine and Growth Factor Reviews, vol. 17, no. 1-2, pp. 41-58, 2006.

[89] E. C. Connolly, J. Freimuth, and R. J. Akhurst, "Complexities of TGF- $\beta$ targeted cancer therapy," International Journal of Biological Sciences, vol. 8, no. 7, pp. 964-978, 2012.

[90] R. Sabat, G. Grütz, K. Warszawska et al., "Biology of interleukin10," Cytokine and Growth Factor Reviews, vol. 21, no. 5, pp. 331344, 2010.

[91] N. L. Costa, M. C. Valadares, P. P. C. Souza et al., "Tumorassociated macrophages and the profile of inflammatory cytokines in oral squamous cell carcinoma," Oral Oncology, vol. 49, no. 3, pp. 216-223, 2013. 
[92] G. A. Gastl, J. S. Abrams, D. M. Nanus et al., "Interleukin-10 production by human carcinoma cell lines and its relationship to interleukin-6 expression," International Journal of Cancer, vol. 55, no. 1, pp. 96-101, 1993.

[93] D. S. Finbloom and K. D. Winestock, "IL-10 induces the tyrosine phosphorylation of tyk2 and Jak1 and the differential assembly of STAT $1 \alpha$ and STAT 3 complexes in human T cells and monocytes," Journal of Immunology, vol. 155, no. 3, pp. 10791090, 1995.

[94] A. J. G. Schottelius, M. W. Mayo, R. Balfour Sartor, and A. S. Baldwin Jr., "Interleukin-10 signaling blocks inhibitor of $\kappa \mathrm{B}$ kinase activity and nuclear factor $\kappa \mathrm{B}$ DNA binding," Journal of Biological Chemistry, vol. 274, no. 45, pp. 31868-31874, 1999.

[95] D. J. Berg, N. Davidson, R. Kühn et al., "Enterocolitis and colon cancer in interleukin-10-deficient mice are associated with aberrant cytokine production and CD4+ Th1-like responses," Journal of Clinical Investigation, vol. 98, no. 4, pp. 1010-1020, 1996.

[96] S. E. Erdman, T. Poutahidis, M. Tomczak et al., "CD4 ${ }^{+} \mathrm{CD} 25^{+}$ regulatory $\mathrm{T}$ lymphocytes inhibit microbially induced colon cancer in Rag2-deficient mice," American Journal of Pathology, vol. 162, no. 2, pp. 691-702, 2003.

[97] S. E. Erdman, V. P. Rao, T. Poutahidis et al., " $\mathrm{CD} 4^{+} \mathrm{CD} 25^{+}$ regulatory lymphocytes require interleukin 10 to interrupt colon carcinogenesis in mice," Cancer Research, vol. 63, no. 18, pp. 6042-6050, 2003.

[98] W.-W. Lin and M. Karin, "A cytokine-mediated link between innate immunity, inflammation, and cancer," Journal of Clinical Investigation, vol. 117, no. 5, pp. 1175-1183, 2007.

[99] N. Kundu and A. M. Fulton, "Interleukin-10 inhibits tumor metastasis, downregulates MHC class I, and enhances NK lysis," Cellular Immunology, vol. 180, no. 1, pp. 55-61, 1997.

[100] H. Hamidullah, B. Changkija, and R. Konwar, "Role of interleukin-10 in breast cancer," Breast Cancer Research and Treatment, vol. 133, no. 1, pp. 11-21, 2012.

[101] D. A. Braun, M. Fribourg, and S. C. Sealfon, "Cytokine response is determined by duration of receptor and signal transducers and activators of transcription 3 (STAT3) activation," Journal of Biological Chemistry, vol. 288, no. 5, pp. 2986-2993, 2013.

[102] B. Sredni, M. Weil, G. Khomenok et al., "Ammonium trichloro(dioxoethylene-o,o')tellurate (AS101) sensitizes tumors to chemotherapy by inhibiting the tumor interleukin 10 autocrine loop," Cancer Research, vol. 64, no. 5, pp. 1843-1852, 2004.

[103] S. Alas, C. Emmanouilides, and B. Bonavida, "Inhibition of interleukin 10 by Rituximab results in down-regulation of Bcl-2 and sensitization of B-cell non-Hodgkin's lymphoma to apoptosis," Clinical Cancer Research, vol. 7, no. 3, pp. 709-723, 2001.

[104] L. Zeng, C. O’Connor, J. Zhang, A. M. Kaplan, and D. A. Cohen, "IL-10 promotes resistance to apoptosis and metastatic potential in lung tumor cell lines," Cytokine, vol. 49, no. 3, pp. 294-302, 2010.

[105] E. Lech-Maranda, J. Bienvenu, A.-S. Michallet et al., "Elevated IL-10 plasma levels correlate with poor prognosis in diffuse large B-cell lymphoma," European Cytokine Network, vol. 17, no. 1, pp. 60-66, 2006.

[106] C. A. Ogden, J. D. Pound, B. K. Batth et al., "Enhanced apoptotic cell clearance capacity and B cell survival factor production by IL-10-activated macrophages: implications for Burkitt's lymphoma," Journal of Immunology, vol. 174, no. 5, pp. 3015-3023, 2005.
[107] K. Bedard and K.-H. Krause, "The NOX family of ROSgenerating NADPH oxidases: physiology and pathophysiology," Physiological Reviews, vol. 87, no. 1, pp. 245-313, 2007.

[108] U. Förstermann and W. C. Sessa, "Nitric oxide synthases: regulation and function," European Heart Journal, vol. 33, no. 7, pp. 829-837, 2012.

[109] R. S. Flannagan, G. Cosío, and S. Grinstein, "Antimicrobial mechanisms of phagocytes and bacterial evasion strategies," Nature Reviews Microbiology, vol. 7, no. 5, pp. 355-366, 2009.

[110] T. Finkel, "Reactive oxygen species and signal transduction," IUBMB Life, vol. 52, no. 1-2, pp. 3-6, 2001.

[111] D. Yang, S. G. Elner, Z.-M. Bian, G. O. Till, H. R. Petty, and V. M. Elner, "Pro-inflammatory cytokines increase reactive oxygen species through mitochondria and NADPH oxidase in cultured RPE cells," Experimental Eye Research, vol. 85, no. 4, pp. 462472, 2007.

[112] A. Sturrock, B. Cahill, K. Norman et al., "Transforming growth factor- $\beta 1$ induces Nox $4 \mathrm{NAD}(\mathrm{P}) \mathrm{H}$ oxidase and reactive oxygen species-dependent proliferation in human pulmonary artery smooth muscle cells," American Journal of Physiology. Lung Cellular and Molecular Physiology, vol. 290, no. 4, pp. L661L673, 2006.

[113] M. da Silva Krause, A. Bittencourt, P. I. Homem de Bittencourt et al., "Physiological concentrations of interleukin- 6 directly promote insulin secretion, signal transduction, nitric oxide release, and redox status in a clonal pancreatic $\beta$-cell line and mouse islets," Journal of Endocrinology, vol. 214, no. 3, pp. 301311, 2012.

[114] G. Rieder, J. A. Hofmann, R. A. Hatz, M. Stolte, and G. A. Enders, "Up-regulation of inducible nitric oxide synthase in Helicobacter pylori-associated gastritis may represent an increased risk factor to develop gastric carcinoma of the intestinal type," International Journal of Medical Microbiology, vol. 293, no. 6, pp. 403-412, 2003.

[115] D. Rachmilewitz, J. S. Stamler, D. Bachwich, F. Karmeli, Z. Ackerman, and D. K. Podolsky, "Enhanced colonic nitric oxide generation and nitric oxide synthase activity in ulcerative colitis and Crohn's disease," Gut, vol. 36, no. 5, pp. 718-723, 1995.

[116] L. J. Hofseth, S. Saito, S. Perwez Hussain et al., "Nitric oxideinduced cellular stress and p53 activation in chronic inflammation," Proceedings of the National Academy of Sciences of the United States of America, vol. 100, no. 1, pp. 143-148, 2003.

[117] N. Ma, Y. Adachi, Y. Hiraku et al., "Accumulation of 8nitroguanine in human gastric epithelium induced by Helicobacter pylori infection," Biochemical and Biophysical Research Communications, vol. 319, no. 2, pp. 506-510, 2004.

[118] S. Horiike, S. Kawanishi, M. Kaito et al., "Accumulation of 8nitroguanine in the liver of patients with chronic hepatitis C," Journal of Hepatology, vol. 43, no. 3, pp. 403-410, 2005.

[119] M. Jaiswal, N. F. LaRusso, R. A. Shapiro, T. R. Billiar, and G. J. Gores, "Nitric oxide-mediated inhibition of DNA repair potentiates oxidative DNA damage in cholangiocytes," Gastroenterology, vol. 120, no. 1, pp. 190-199, 2001.

[120] C.-H. Tang, W. Wei, and L. Liu, "Regulation of DNA repair by S-nitrosylation," Biochimica et Biophysica Acta, vol. 1820, no. 6, pp. 730-735, 2012.

[121] Q. Li, G.-B. Fu, J.-T. Zheng et al., "NADPH oxidase subunit p22(phox)-mediated reactive oxygen species contribute to angiogenesis and tumor growth through AKT and ERK1/2 signaling pathways in prostate cancer," Biochimica et Biophysica Acta, vol. 1833, no. 12, pp. 3375-3385, 2013. 
[122] S.-N. Jung, W. K. Yang, J. Kim et al., "Reactive oxygen species stabilize hypoxia-inducible factor-1 alpha protein and stimulate transcriptional activity via AMP-activated protein kinase in DU145 human prostate cancer cells," Carcinogenesis, vol. 29, no. 4, pp. 713-721, 2008.

[123] C. V. Rao, C. Indranie, B. Simi, P. T. Manning, J. R. Connor, and B. S. Reddy, "Chemopreventive properties of a selective inducible nitric oxide synthase inhibitor in colon carcinogenesis, administered alone or in combination with celecoxib, a selective cyclooxygenase-2 inhibitor," Cancer Research, vol. 62, no. 1, pp. 165-170, 2002.

[124] M. Takahashi, T. Kitahashi, R. Ishigamori et al., "Increased expression of inducible nitric oxide synthase (iNOS) in $\mathrm{N}$-nitrosobis(2-oxopropyl)amine-induced hamster pancreatic carcinogenesis and prevention of cancer development by ONO1714, an iNOS inhibitor," Carcinogenesis, vol. 29, no. 8, pp. 16081613, 2008.

[125] B. Li, R. Alli, P. Vogel, and T. L. Geiger, "IL-10 modulates DSSinduced colitis through a macrophage-ROS-NO axis," Mucosal Immunology, 2013.

[126] G. Zhu, Q. Du, X. Wang et al., "TNF- $\alpha$ promotes gallbladder cancer cell growth and invasion through autocrine mechanisms," International Journal of Molecular Medicine, 2014.

[127] K. A. Charles, H. Kulbe, R. Soper et al., “The tumor-promoting actions of TNF- $\alpha$ involve TNFR1 and IL-17 in ovarian cancer in mice and humans," Journal of Clinical Investigation, vol. 119, no. 10, pp. 3011-3023, 2009.

[128] D. He, H. Li, N. Yusuf et al., "IL-17 mediated inflammation promotes tumor growth and progression in the skin," PLoS ONE, vol. 7, no. 2, Article ID e32126, 2012.

[129] T. Shouda, K. Hiraoka, S. Komiya et al., "Suppression of IL-6 production and proliferation by blocking STAT3 activation in malignant soft tissue tumor cells," Cancer Letters, vol. 231, no. 2, pp. 176-184, 2006.

[130] Q. Tang, J. Li, H. Zhu et al., "Hmgb1-IL-23-IL-17-IL-6-Stat3 axis promotes tumor growth in murine models of melanoma," Mediators of Inflammation, vol. 2013, Article ID 713859, 13 pages, 2013.

[131] T. Zheng, X. Hong, and J. Wang, "Gankyrin promotes tumor growth and metastasis through activation of IL-6/STAT3 signaling in human cholangiocarcinoma," Hepatology, vol. 59, no. 3, pp. 935-946, 2014.

[132] Y. Dai, H. Jiao, G. Teng et al., "Embelin reduces colitisassociated tumorigenesis through limiting IL-6/STAT3 signaling," Molecular Cancer Therapeutics, 2014.

[133] M. L. García-Hernández, R. Hernández-Pando, P. Gariglio, and J. Berumen, "Interleukin-10 promotes B16-melanoma growth by inhibition of macrophage functions and induction of tumour and vascular cell proliferation," Immunology, vol. 105, no. 2, pp. 231-243, 2002.

[134] B. Baum, J. Settleman, and M. P. Quinlan, "Transitions between epithelial and mesenchymal states in development and disease," Seminars in Cell and Developmental Biology, vol. 19, no. 3, pp. 294-308, 2008.

[135] R. Kalluri and R. A. Weinberg, "The basics of epithelialmesenchymal transition," Journal of Clinical Investigation, vol. 119, no. 6, pp. 1420-1428, 2009.

[136] J. P. Thiery and J. P. Sleeman, "Complex networks orchestrate epithelial-mesenchymal transitions," Nature Reviews Molecular Cell Biology, vol. 7, no. 2, pp. 131-142, 2006.
[137] J. Xu, S. Lamouille, and R. Derynck, “TGF-B-induced epithelial to mesenchymal transition," Cell Research, vol. 19, no. 2, pp. 156$172,2009$.

[138] J. P. Thiery, "Epithelial-mesenchymal transitions in tumour progression," Nature Reviews Cancer, vol. 2, no. 6, pp. 442-454, 2002.

[139] V. Tirino, R. Camerlingo, K. Bifulco et al., “TGF- $\beta 1$ exposure induces epithelial to mesenchymal transition both in CSCs and non-CSCs of the A549 cell line, leading to an increase of migration ability in the CD133+ A549 cell fraction," Cell Death \& Disease, vol. 4, no. 5, article e620, 2013.

[140] V. Ellenrieder, S. F. Hendler, W. Boeck et al., "Transforming growth factor $\beta 1$ treatment leads to an epithelial-mesenchymal transdifferentiation of pancreatic cancer cells requiring extracellular signal-regulated kinase 2 activation," Cancer Research, vol. 61, no. 10, pp. 4222-4228, 2001.

[141] B. C. Willis, J. M. Liebler, K. Luby-Phelps et al., "Induction of epithelial-mesenchymal transition in alveolar epithelial cells by transforming growth factor- $\beta 1$ : potential role in idiopathic pulmonary fibrosis," American Journal of Pathology, vol. 166, no. 5, pp. 1321-1332, 2005.

[142] T. Yamagishi, K. Ando, H. Nakamura, and Y. Nakajima, "Expression of the Tgf $\beta 2$ gene during chick embryogenesis," Anatomical Record, vol. 295, no. 2, pp. 257-267, 2012.

[143] M. Sato, Y. Muragaki, S. Saika, A. B. Roberts, and A. Ooshima, "Targeted disruption of TGF- $\beta 1 / \mathrm{Smad} 3$ signaling protects against renal tubulointerstitial fibrosis induced by unilateral ureteral obstruction," Journal of Clinical Investigation, vol. 112, no. 10, pp. 1486-1494, 2003.

[144] U. Valcourt, M. Kowanetz, H. Niimi, C.-H. Heldin, and A. Moustakas, "TGF- $\beta$ and the Smad signaling pathway support transcriptomic reprogramming during epithelial-mesenchymal cell transition," Molecular Biology of the Cell, vol. 16, no. 4, pp. 1987-2002, 2005.

[145] A. Abulaiti, Y. Shintani, S. Funaki et al., "Interaction between non-small-cell lung cancer cells and fibroblasts via enhancement of TGF- $\beta$ signaling by IL-6," Lung Cancer, vol. 82, no. 2 , pp. 204-213, 2013.

[146] H. J. Maier, U. Schmidt-Straßburger, M. A. Huber, E. M. Wiedemann, H. Beug, and T. Wirth, "NF- $\kappa$ B promotes epithelialmesenchymal transition, migration and invasion of pancreatic carcinoma cells," Cancer Letters, vol. 295, no. 2, pp. 214-228, 2010.

[147] M. Kumar, D. F. Allison, N. N. Baranova et al., "NF- $\kappa$ B regulates mesenchymal transition for the induction of non-small cell lung cancer initiating cells," PLoS ONE, vol. 8, no. 7, Article ID e68597, 2013.

[148] A. Yadav, B. Kumar, J. Datta, T. N. Teknos, and P. Kumar, "IL-6 promotes head and neck tumor metastasis by inducing epithelial-mesenchymal transition via the JAK-STAT3-SNAIL signaling pathway," Molecular Cancer Research, vol. 9, no. 12, pp. 1658-1667, 2011.

[149] Z. Wang, Y. Li, and F. H. Sarkar, "Signaling mechanism(S) of reactive oxygen species in epithelial-mesenchymal transition reminiscent of cancer stem cells in tumor progression," Current Stem Cell Research and Therapy, vol. 5, no. 1, pp. 74-80, 2010.

[150] D. Y. Rhyu, Y. Yang, H. Ha et al., "Role of reactive oxygen species in TGF- $\beta 1$-induced mitogen-activated protein kinase activation and epithelial-mesenchymal transition in renal tubular epithelial cells," Journal of the American Society of Nephrology, vol. 16, no. 3, pp. 667-675, 2005. 
[151] Y. Cao, "Tumor angiogenesis and therapy," Biomedicine and Pharmacotherapy, vol. 59, no. 2, pp. S340-S343, 2005.

[152] O.-H. Kim, G.-H. Kang, H. Noh et al., "Proangiogenic $\mathrm{TIE} 2^{+} / \mathrm{CD} 31^{+}$) macrophages are the predominant population of tumor-associated macrophages infiltrating metastatic lymph nodes," Molecules and Cells, vol. 36, no. 5, pp. 432-438, 2013.

[153] L. F. Fajardo, H. H. Kwan, J. Kowalski, S. D. Prionas, and A. C. Allison, "Dual role of tumor necrosis factor- $\alpha$ in angiogenesis," American Journal of Pathology, vol. 140, no. 3, pp. 539-544, 1992.

[154] R. R. Weichselbaum, D. W. Kufe, S. Hellman et al., "Radiationinduced tumour necrosis factor- $\alpha$ expression: clinical application of transcriptional and physical targeting of gene therapy," The Lancet Oncology, vol. 3, no. 11, pp. 665-671, 2002.

[155] S. Yoshida, M. Ono, T. Shono et al., "Involvement of interleukin8, vascular endothelial growth factor, and basic fibroblast growth factor in tumor necrosis factor alpha-dependent angiogenesis," Molecular and Cellular Biology, vol. 17, no. 7, pp. 40154023, 1997.

[156] B. Li, A. Vincent, J. Cates, D. M. Brantley-Sieders, D. B. Polk, and P. P. Young, "Low levels of tumor necrosis factor $\alpha$ increase tumor growth by inducing an endothelial phenotype of monocytes recruited to the tumor site," Cancer Research, vol. 69, no. 1, pp. 338-348, 2009.

[157] H. Kulbe, R. Thompson, J. L. Wilson et al., "The inflammatory cytokine tumor necrosis factor- $\alpha$ generates an autocrine tumorpromoting network in epithelial ovarian cancer cells," Cancer Research, vol. 67, no. 2, pp. 585-592, 2007.

[158] A. Eldesoky, A. Shouma, Y. Mosaad, and A. Elhawary, "Clinical relevance of serum vascular endothelial growth factor and interleukin-6 in patients with colorectal cancer," Saudi Journal of Gastroenterology, vol. 17, no. 3, pp. 170-173, 2011.

[159] H. K. Kim, K. S. Song, Y. S. Park et al., "Elevated levels of circulating platelet microparticles, VEGF, IL-6 and RANTES in patients with gastric cancer: possible role of a metastasis predictor," European Journal of Cancer, vol. 39, no. 2, pp. 184191, 2003.

[160] S.-P. Huang, M.-S. Wu, C.-T. Shun et al., "Interleukin-6 increases vascular endothelial growth factor and angiogenesis in gastric carcinoma," Journal of Biomedical Science, vol. 11, no. 4, pp. 517-527, 2004.

[161] L.-H. Wei, M.-L. Kuo, C.-A. Chen et al., "Interleukin-6 promotes cervical tumor growth by VEGF-dependent angiogenesis via a STAT3 pathway," Oncogene, vol. 22, no. 10, pp. 1517-1527, 2003.

[162] L. W. Feurino, Y. Zhang, U. Bharadwaj et al., "IL-6 stimulates Th2 type cytokine secretion and upregulates VEGF and NRP1 expression in pancreatic cancer cells," Cancer Biology and Therapy, vol. 6, no. 7, pp. 1096-1100, 2007.

[163] S. R. Boreddy, R. P. Sahu, and S. K. Srivastava, "Benzyl isothiocyanate suppresses pancreatic tumor angiogenesis and invasion by inhibiting HIF- $\alpha$ /VEGF/Rho-GTPases: pivotal role of STAT-3," PLoS ONE, vol. 6, no. 10, Article ID e25799, 2011.

[164] P. Wikström, P. Stattin, I. Franck-Lissbrant et al., “Transforming growth factor betal is associated with angiogenesis, metastasis, and poor clinical outcome in prostate cancer," Prostate, vol. 37, no. 1, pp. 19-29, 1998.

[165] H. Saito, S. Tsujitani, S. Oka et al., "The expression of transforming growth factor-betal is significantly correlated with the expression of vascular endothelial growth factor and poor prognosis of patients with advanced gastric carcinoma," Cancer, vol. 86, no. 8, pp. 1455-1462, 1999.
[166] M. C. Dickson, J. S. Martin, F. M. Cousins, A. B. Kulkarni, S. Karlsson, and R. J. Akhurst, "Defective haematopoiesis and vasculogenesis in transforming growth factor- $\beta 1$ knock out mice," Development, vol. 121, no. 6, pp. 1845-1854, 1995.

[167] S. Huang, K. Xie, C. D. Bucana, S. E. Ullrich, and M. BarEli, "Interleukin 10 suppresses tumor growth and metastasis of human melanoma cells: potential inhibition of angiogenesis," Clinical Cancer Research, vol. 2, no. 12, pp. 1969-1979, 1996.

[168] M. E. Stearns, J. Rhim, and M. Wang, "Interleukin 10 (IL-10) inhibition of primary human prostate cell- induced angiogenesis: IL-10 stimulation of tissue inhibitor of metalloproteinase-1 and inhibition of matrix metalloproteinase (MMP)-2/MMP-9 secretion," Clinical Cancer Research, vol. 5, no. 1, pp. 189-196, 1999.

[169] T. Kohno, H. Mizukami, M. Suzuki et al., "Interleukin-10mediated inhibition of angiogenesis and tumor growth in mice bearing VEGF-producing ovarian cancer," Cancer Research, vol. 63, no. 16, pp. 5091-5094, 2003.

[170] P. Orosz, B. Echtenacher, W. Falk, J. Ruschoff, D. Weber, and D. N. Mannel, "Enhancement of experimental metastasis by tumor necrosis factor," Journal of Experimental Medicine, vol. 177, no. 5, pp. 1391-1398, 1993.

[171] P. Orosz, A. Kruger, M. Hubbe, J. Ruschoff, P. Von Hoegen, and D. N. Mannel, "Promotion of experimental liver metastasis by tumor necrosis factor," International Journal of Cancer, vol. 60, no. 6, pp. 867-871, 1995.

[172] S. Kim, H. Takahashi, W.-W. Lin et al., "Carcinoma-produced factors activate myeloid cells through TLR2 to stimulate metastasis," Nature, vol. 457, no. 7225, pp. 102-106, 2009.

[173] J.-H. Egberts, V. Cloosters, A. Noack et al., "Anti-tumor necrosis factor therapy inhibits pancreatic tumor growth and metastasis," Cancer Research, vol. 68, no. 5, pp. 1443-1450, 2008.

[174] G. D. Roodman, "Role of stromal-derived cytokines and growth factors in bone metastasis," Cancer, vol. 97, no. 3, pp. 733-738, 2003.

[175] K. Tawara, J. T. Oxford, and C. L. Jorcyk, "Clinical significance of interleukin (IL)-6 in cancer metastasis to bone:Potential of anti-IL-6 therapies," Cancer Management and Research, vol. 3, no. 1, pp. 177-189, 2011.

[176] T. R. Samatov, A. G. Tonevitsky, and U. Schumacher, "Epithelialmesenchymal transition: focus on metastatic cascade, alternative splicing, non-coding RNAs and modulating compounds," Molecular Cancer, vol. 12, no. 1, article 107, 2013.

[177] J. Ferlay, H.-R. Shin, F. Bray, D. Forman, C. Mathers, and D. M. Parkin, "Estimates of worldwide burden of cancer in 2008: GLOBOCAN 2008," International Journal of Cancer, vol. 127, no. 12, pp. 2893-2917, 2010.

[178] R. Siegel, D. Naishadham, and A. Jemal, "Cancer statistics, 2013," CA Cancer Journal for Clinicians, vol. 63, pp. 11-30, 2013.

[179] C. J. Ooi, K. M. Fock, G. K. Makharia et al., "The Asia-Pacific consensus on ulcerative colitis," Journal of Gastroenterology and Hepatology, vol. 25, no. 3, pp. 453-468, 2010.

[180] T. Watanabe, T. Konishi, J. Kishimoto, K. Kotake, T. Muto, and K. Sugihara, "Ulcerative colitis-associated colorectal cancer shows a poorer survival than sporadic colorectal cancer: a nationwide Japanese study," Inflammatory Bowel Diseases, vol. 17, no. 3, pp. 802-808, 2011.

[181] T. A. Ullman and S. H. Itzkowitz, "Intestinal inflammation and cancer," Gastroenterology, vol. 140, no. 6, pp. 1807-1816, 2011.

[182] R. M. Soetikno, O. S. Lin, P. A. Heidenreich, H. S. Young, and M. O. Blackstone, "Increased risk of colorectal neoplasia 
in patiets with primary sclerosing cholangitis and ulcerative colitis: a meta-analysis," Gastrointestinal Endoscopy, vol. 56, no. 1, pp. 48-54, 2002.

[183] B. Chassaing and A. Darfeuillemichaud, "The commensal microbiota and enteropathogens in the pathogenesis of inflammatory bowel diseases," Gastroenterology, vol. 140, no. 6, pp. 1720-1728, 2011.

[184] M. de la Fuente, L. Franchi, and D. Araya, "Escherichia coli isolates from inflammatory bowel diseases patients survive in macrophages and activate NLRP3 inflammasome," International Journal of Medical Microbiology, 2014.

[185] M. Sasaki, S. V. Sitaraman, B. A. Babbin et al., "Invasive Escherichia coli are a feature of Crohn's disease," Laboratory Investigation, vol. 87, no. 10, pp. 1042-1054, 2007.

[186] H. Nakase, H. Tamaki, M. Matsuura, T. Chiba, and K. Okazaki, "Involvement of Mycobacterium avium subspecies paratuberculosis in TNF- $\alpha$ production from macrophage: possible link between MAP and immune response in Crohn's disease," Inflammatory Bowel Diseases, vol. 17, no. 11, pp. e140-e142, 2011.

[187] E. Mizoguchi, M. Kanneganti, and M. Mino-Kenudson, "Animal models of colitis-associated carcinogenesis," Journal of Biomedicine and Biotechnology, vol. 2011, Article ID 342637, 23 pages, 2011.

[188] I. Okayasu, M. Yamada, T. Mikami, T. Yoshida, J. Kanno, and T. Ohkusa, "Dysplasia and carcinoma development in a repeated dextran sulfate sodium-induced colitis model," Journal of Gastroenterology and Hepatology, vol. 17, no. 10, pp. 1078-1083, 2002.

[189] H. S. Cooper, S. Murthy, K. Kido, H. Yoshitake, and A. Flanigan, "Dysplasia and cancer in the dextran sulfate sodium mouse colitis model. Relevance to colitis-associated neoplasia in the human: a study of histopathology, B-catenin and p53 expression and the role of inflammation," Carcinogenesis, vol. 21, no. 4, pp. 757-768, 2000.

[190] T. Tanaka, H. Kohno, R. Suzuki, Y. Yamada, S. Sugie, and H. Mori, "A novel inflammation-related mouse colon carcinogenesis model induced by azoxymethane and dextran sodium sulfate," Cancer Science, vol. 94, no. 11, pp. 965-973, 2003.

[191] M. Takahashi, M. Mutoh, T. Kawamori, T. Sugimura, and K. Wakabayashi, "Altered expression of $\beta$-catenin, inducible nitric oxide synthase and cyclooxygenase- 2 in azoxymethaneinduced rat colon carcinogenesis," Carcinogenesis, vol. 21, no. 7, pp. 1319-1327, 2000.

[192] T. Olsen, R. Goll, G. Cui et al., "Tissue levels of tumor necrosis factor-alpha correlates with grade of inflammation in untreated ulcerative colitis," Scandinavian Journal of Gastroenterology, vol. 42, no. 11, pp. 1312-1320, 2007.

[193] K. Kusugami, A. Fukatsu, M. Tanimoto et al., "Elevation of interleukin-6 in inflammatory bowel disease is macrophageand epithelial cell-dependent," Digestive Diseases and Sciences, vol. 40, no. 5, pp. 949-959, 1995.

[194] B. K. Popivanova, K. Kitamura, Y. Wu et al., "Blocking TNF- $\alpha$ in mice reduces colorectal carcinogenesis associated with chronic colitis," Journal of Clinical Investigation, vol. 118, no. 2, pp. 560$570,2008$.

[195] D. N. Seril, J. Liao, G.-Y. Yang, and C. S. Yang, "Oxidative stress and ulcerative colitis-associated carcinogenesis: studies in humans and animal models," Carcinogenesis, vol. 24, no. 3, pp. 353-362, 2003.

[196] S. P. Hussain, P. Amstad, K. Raja et al., "Increased p53 mutation load in noncancerous colon tissue from ulcerative colitis: a cancer-prone chronic inflammatory disease," Cancer Research, vol. 60, no. 13, pp. 3333-3337, 2000.

[197] H. Tsushima, S. Kawata, S. Tamura et al., "High levels of transforming growth factor in patients with colorectal cancer: association with disease progression," Gastroenterology, vol.110, no. 2, pp. 375-382, 1996.

[198] I. C. Lawrance, L. Maxwell, and W. Doe, "Inflammation location, but not type, determines the increase in TGF- $\beta 1$ and IGF-1 expression and collagen deposition in IBD intestine," Inflammatory Bowel Diseases, vol. 7, no. 1, pp. 16-26, 2001.

[199] F. Scaldaferri, S. Vetrano, M. Sans et al., "VEGF-A links angiogenesis and inflammation in inflammatory bowel disease pathogenesis," Gastroenterology, vol. 136, no. 2, pp. 585-595, 2009.

[200] M. J. Waldner, S. Wirtz, A. Jefremow et al., "VEGF receptor signaling links inflammation and tumorigenesis in colitisassociated cancer," Journal of Experimental Medicine, vol. 207, no. 13, pp. 2855-2868, 2010.

[201] Y. Kikuchi, T. G. Kashima, T. Nishiyama et al., "Periostin is expressed in pericryptal fibroblasts and cancer-associated fibroblasts in the colon," Journal of Histochemistry and Cytochemistry, vol. 56, no. 8, pp. 753-764, 2008.

[202] S. Bao, G. Ouyang, X. Bai et al., "Periostin potently promotes metastatic growth of colon cancer by augmenting cell survival via the Akt/PKB pathway," Cancer Cell, vol. 5, no. 4, pp. 329-339, 2004.

[203] S. Fujino, A. Andoh, S. Bamba et al., "Increased expression of interleukin 17 in inflammatory bowel disease," Gut, vol. 52, no. 1, pp. 65-70, 2003.

[204] Y. S. Hyun, D. S. Han, A. R. Lee, C. S. Eun, J. Youn, and H.-Y. Kim, "Role of IL-17A in the development of colitis-associated cancer," Carcinogenesis, vol. 33, no. 4, pp. 931-936, 2012.

[205] M. A. Farrar and R. D. Schreiber, "The molecular cell biology of interferon- $\gamma$ and its receptor," Annual Review of Immunology, vol. 11, pp. 571-611, 1993.

[206] A. Harada, N. Sekido, T. Akahoshi, T. Wada, N. Mukaida, and K. Matsushima, "Essential involvement of interleukin-8 (IL-8) in acute inflammation," Journal of Leukocyte Biology, vol. 56, no. 5, pp. 559-564, 1994.

[207] R. Daig, T. Andus, E. Aschenbrenner, W. Falk, J. Schölmerich, and V. Gross, "Increased interleukin 8 expression in the colon mucosa of patients with inflammatory bowel disease," Gut, vol. 38, no. 2, pp. 216-222, 1996.

[208] L. Mazzucchelli, C. Hauser, K. Zgraggen et al., "Expression of interleukin-8 gene in inflammatory bowel disease is related to the histological grade of active inflammation," American Journal of Pathology, vol. 144, no. 5, pp. 997-1007, 1994.

[209] M. C. Grimm, S. K. O. Elsbury, P. Pavli, and W. F. Doe, "Interleukin 8: cells of origin in inflammatory bowel disease," Gut, vol. 38, no. 1, pp. 90-98, 1996.

[210] A. Li, M. L. Varney, and R. K. Singh, "Expression of interleukin 8 and its receptors in human colon carcinoma cells with different metastatic potentials," Clinical Cancer Research, vol. 7, no. 10, pp. 3298-3304, 2001.

[211] T. Cacev, S. Radosević, S. Krizanac, and S. Kapitanović, "Influence of interleukin-8 and interleukin-10 on sporadic colon cancer development and progression," Carcinogenesis, vol. 29, no. 8, pp. 1572-1580, 2008.

[212] J. Heidemann, H. Ogawa, M. B. Dwinell et al., "Angiogenic effects of interleukin 8 (CXCL8) in human intestinal microvascular endothelial cells are mediated by CXCR2," Journal of Biological Chemistry, vol. 278, no. 10, pp. 8508-8515, 2003. 
[213] J. E. Everhart and C. E. Ruhl, "Burden of digestive diseases in the United States-part III: liver, biliary tract, and pancreas," Gastroenterology, vol. 136, no. 4, pp. 1134-1144, 2009.

[214] Y. Shaib and H. B. El-Serag, "The epidemiology of cholangiocarcinoma," Seminars in Liver Disease, vol. 24, no. 2, pp. 115-125, 2004.

[215] B. Sripa and C. Pairojkul, "Cholangiocarcinoma: lessons from Thailand," Current Opinion in Gastroenterology, vol. 24, no. 3, pp. 349-356, 2008.

[216] G. L. Tyson and H. B. El-Serag, "Risk factors for cholangiocarcinoma," Hepatology, vol. 54, no. 1, pp. 173-184, 2011.

[217] J. Fevery, C. Verslype, G. Lai, R. Aerts, and W. van Steenbergen, "Incidence, diagnosis, and therapy of cholangiocarcinoma in patients with primary sclerosing cholangitis," Digestive Diseases and Sciences, vol. 52, no. 11, pp. 3123-3135, 2007.

[218] P. Charatcharoenwitthaya, F. B. Enders, K. C. Halling, and K. D. Lindor, "Utility of serum tumor markers, imaging, and biliary cytology for detecting cholangiocarcinoma in primary sclerosing cholangitis," Hepatology, vol. 48, no. 4, pp. 1106-1117, 2008.

[219] K. Burak, P. Angulo, T. M. Pasha, K. Egan, J. Petz, and K. D. Lindor, "Incidence and risk factors for cholangiocarcinoma in primary sclerosing cholangitis," American Journal of Gastroenterology, vol. 99, no. 3, pp. 523-526, 2004.

[220] V. Bouvard, R. Baan, K. Straif et al., "A review of human carcinogens-part B: biological agents," The Lancet Oncology, vol. 10, no. 4, pp. 321-322, 2009.

[221] B. Sripa, J. M. Bethony, P. Sithithaworn et al., "Opisthorchiasis and Opisthorchis-associated cholangiocarcinoma in Thailand and Laos," Acta Tropica, vol. 120, no. 1, pp. S158-S168, 2011.

[222] K. L. Min, Y.-H. Ju, S. Franceschi et al., "Clonorchis sinensis infection and increasing risk of cholangiocarcinoma in the republic of korea," American Journal of Tropical Medicine and Hygiene, vol. 75, no. 1, pp. 93-96, 2006.

[223] X. Zhou, W. Peng, D. W. T. Crompton, and J. Xiong, "Treatment of biliary ascariasis in China," Transactions of the Royal Society of Tropical Medicine and Hygiene, vol. 93, no. 6, pp. 561-564, 1999.

[224] M. Mukhopadhyay, "Biliary ascariasis in the Indian subcontinent: a study of 42 cases," Saudi Journal of Gastroenterology, vol. 15, no. 2, pp. 121-124, 2009.

[225] A. M. Di Bisceglie, "Hepatitis B and hepatocellular carcinoma," Hepatology, vol. 49, no. 5, pp. S56-S60, 2009.

[226] T. Y. Lee, S. S. Lee, S. W. Jung et al., "Hepatitis B virus infection and intrahepatic cholangiocarcinoma in Korea: a case-control study," American Journal of Gastroenterology, vol. 103, no. 7, pp. 1716-1720, 2008.

[227] T. Isa, S. Tomita, A. Nakachi et al., "Analysis of microsatellite instability, K-ras gene mutation and $\mathrm{p} 53$ protein overexpression in intrahepatic cholangiocarcinoma," Hepato-Gastroenterology, vol. 49, no. 45, pp. 604-608, 2002.

[228] Y. Wang, Y. Yamaguchi, H. Watanabe, K. Ohtsubo, T. Wakabayashi, and N. Sawabu, "Usefulness of p53 gene mutations in the supernatant of bile for diagnosis of biliary tract carcinoma: comparison with K-ras mutation," Journal of Gastroenterology, vol. 37, no. 10, pp. 831-839, 2002.

[229] T. Itoi, K. Takei, Y. Shinohara et al., "K-ras codon 12 and p53 mutations in biopsy specimens and bile from biliary tract cancers," Pathology International, vol. 49, no. 1, pp. 30-37, 1999.

[230] S.-I. Aishima, K.-I. Taguchi, K. Sugimachi, M. Shimada, K. Sugimachi, and M. Tsuneyoshi, "c-erbB-2 and c-Met expression relates to cholangiocarcinogenesis and progression of intrahepatic cholangiocarcinoma," Histopathology, vol. 40, no. 3, pp. 269-278, 2002.

[231] A. C. Okaro, A. R. Deery, R. R. Hutchins, and B. R. Davidson, "The expression of antiapoptotic proteins $\mathrm{Bcl}-2, \mathrm{Bcl}-\mathrm{xL}$, and Mcl-1 in benign, dysplastic, and malignant biliary epithelium," Journal of Clinical Pathology, vol. 54, no. 12, pp. 927-932, 2001.

[232] M. Taniai, H. Higuchi, L. J. Burgart, and G. J. Gores, "p16INK4a promoter mutations are frequent in primary sclerosing cholangitis (PSC) and PSC-associated cholangiocarcinoma," Gastroenterology, vol. 123, no. 4, pp. 1090-1098, 2002.

[233] S. Boonjaraspinyo, Z. Wu, T. Boonmars et al., "Overexpression of PDGFA and its receptor during carcinogenesis of Opisthorchis viverrini-associated cholangiocarcinoma," Parasitology International, vol. 61, no. 1, pp. 145-150, 2012.

[234] S. Boonjaraspinyo, T. Boonmars, Z. Wu et al., "Platelet-derived growth factor may be a potential diagnostic and prognostic marker for cholangiocarcinoma," Tumor Biology, vol. 33, no. 5, pp. 1785-1802, 2012.

[235] D. J. Drucker, "Biological actions and therapeutic potential of the glucagon-like peptides," Gastroenterology, vol. 122, no. 2, pp. 531-544, 2002.

[236] M. Marzioni, G. Alpini, S. Saccomanno et al., "Glucagon-like peptide-1 and its receptor agonist exendin-4 modulate cholangiocyte adaptive response to cholestasis," Gastroenterology, vol. 133, no. 1, pp. 244-255, 2007.

[237] E. Gaudio, B. Barbaro, D. Alvaro et al., "Vascular endothelial growth factor stimulates rat cholangiocyte proliferation via an autocrine mechanism," Gastroenterology, vol. 130, no. 4, pp. 1270-1282, 2006.

[238] E. Gaudio, B. Barbaro, D. Alvaro et al., "Administration of r-VEGF-A prevents hepatic artery ligation-induced bile duct damage in bile duct ligated rats," American Journal of Physiology. Gastrointestinal and Liver Physiology, vol. 291, no. 2, pp. G307G317, 2006.

[239] A. E. Sirica, M. H. Nathanson, G. J. Gores, and N. F. LaRusso, "Pathobiology of biliary epithelia and cholangiocarcinoma: proceedings of the Henry M. and Lillian Stratton Basic Research Single-Topic Conference," Hepatology, vol. 48, no. 6, pp. 20402046, 2008.

[240] D. Hanahan and L. M. Coussens, "Accessories to the crime: functions of cells recruited to the tumor microenvironment," Cancer Cell, vol. 21, no. 3, pp. 309-322, 2012.

[241] C. Chuaysri, P. Thuwajit, A. Paupairoj, S. Chau-In, T. Suthiphongchai, and C. Thuwajit, "Alpha-smooth muscle actin-positive fibroblasts promote biliary cell proliferation and correlate with poor survival in cholangiocarcinoma," Oncology Reports, vol. 21, no. 4, pp. 957-969, 2009.

[242] K. Utispan, P. Thuwajit, Y. Abiko et al., "Gene expression profiling of cholangiocarcinoma-derived fibroblast reveals alterations related to tumor progression and indicates periostin as a poor prognostic marker," Molecular Cancer, vol. 9, article 13, 2010.

[243] A. E. Sirica, "The role of cancer-associated myofibroblasts in intrahepatic cholangiocarcinoma," Nature Reviews Gastroenterology and Hepatology, vol. 9, no. 1, pp. 44-54, 2012.

[244] S. Rizvi and G. J. Gores, "Pathogenesis, diagnosis, and management of cholangiocarcinoma," Gastroenterology, vol. 145, no. 6, pp. 1215-1229, 2013.

[245] A. E. Sirica, D. J. Campbell, and C. I. Dumur, "Cancer-associated fibroblasts in intrahepatic cholangiocarcinoma," Current Opinion in Gastroenterology, vol. 27, no. 3, pp. 276-284, 2011. 


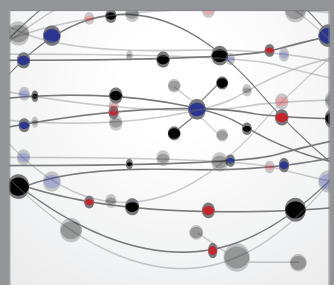

The Scientific World Journal
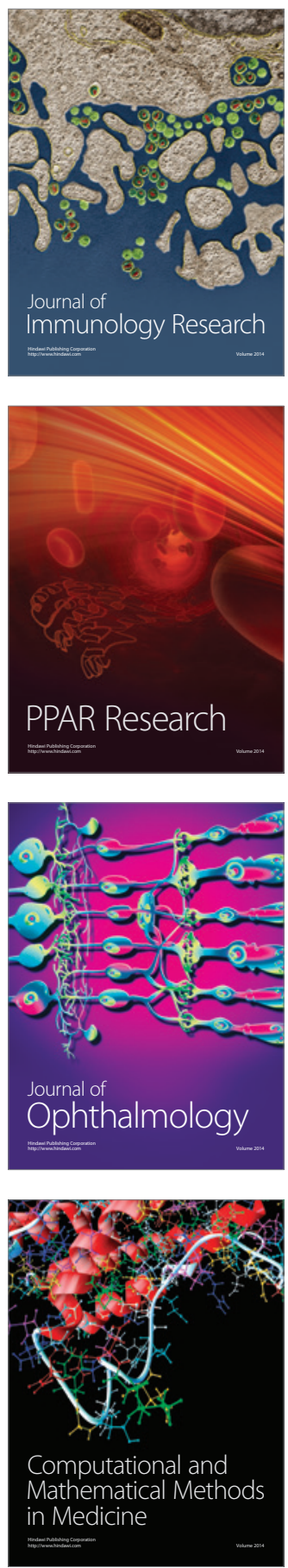

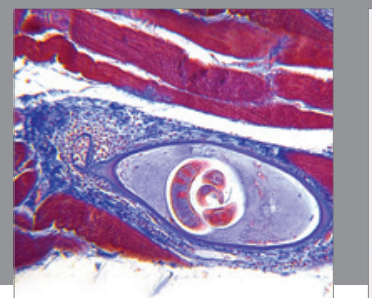

Gastroenterology

Research and Practice
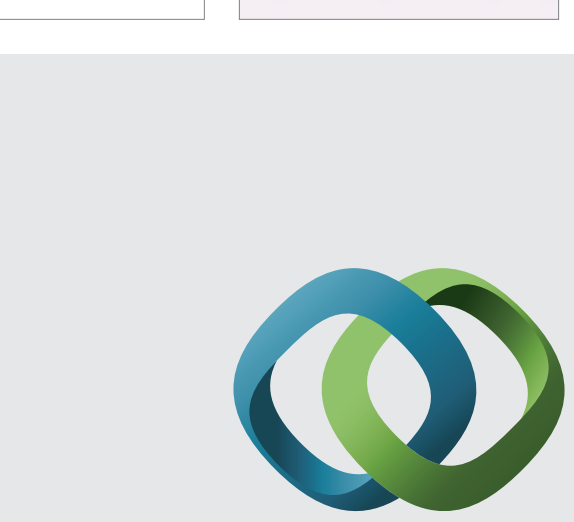

\section{Hindawi}

Submit your manuscripts at

http://www.hindawi.com
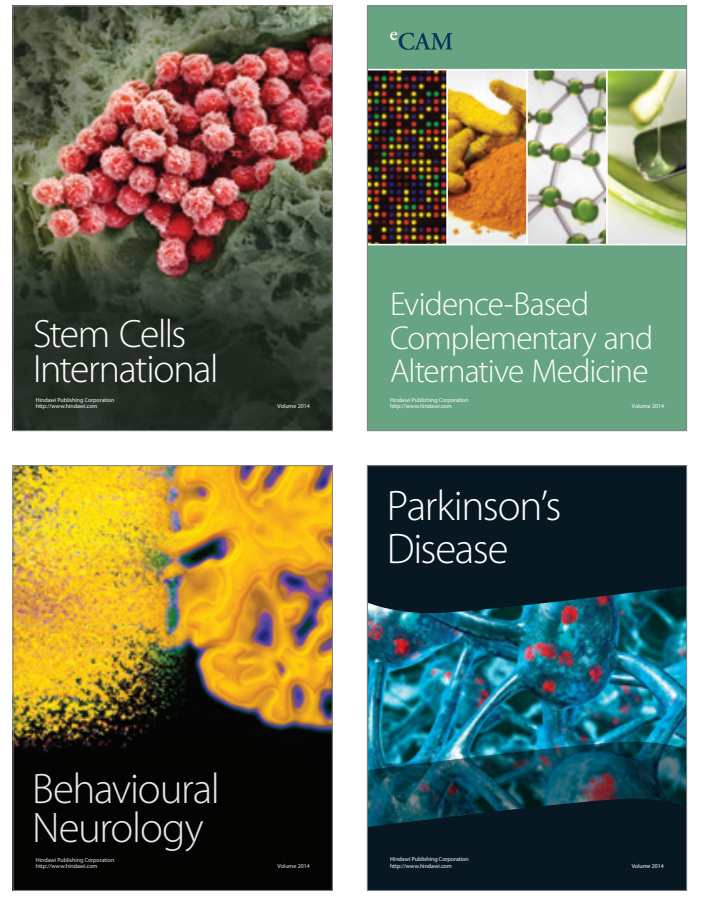
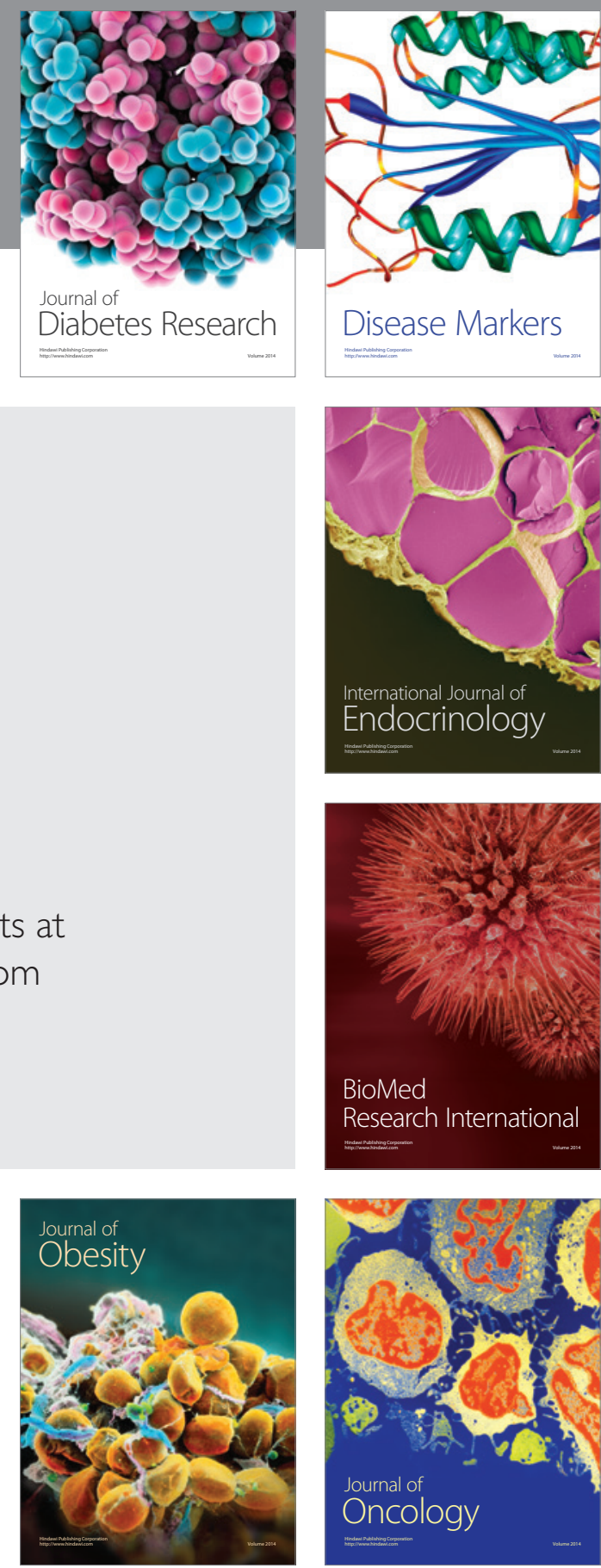

Disease Markers
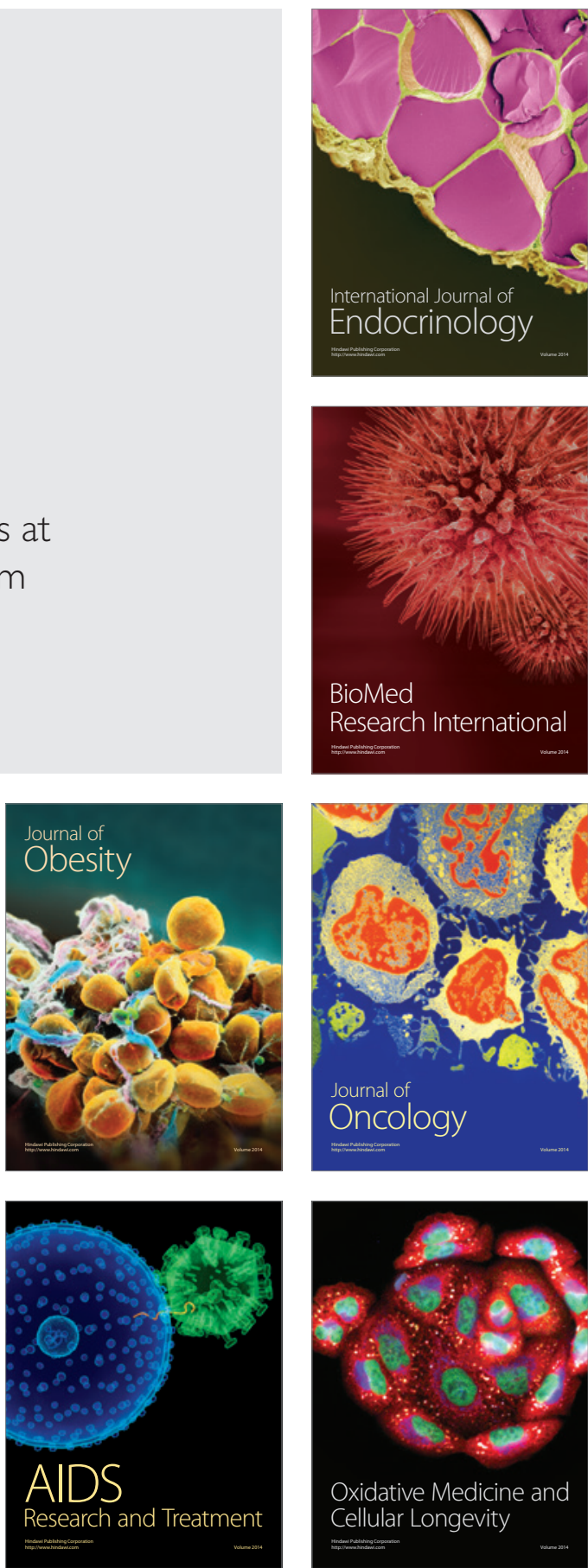